\title{
38. ENVIRONMENTAL CONTROL OF MAGNETIC PROPERTIES OF UPPER-SLOPE SEDIMENTS NEAR THE GREAT BARRIER REEF: RESULTS FROM LEG 133, SITE 820
}

\author{
C.E. Barton, ${ }^{2}$ M. Lackie, ${ }^{2,3}$ and F.M. Peerdeman ${ }^{4}$
}

\begin{abstract}
Paleomagnetic analysis of sediment samples from Ocean Drilling Program (ODP) Leg 133, Site 820, $10 \mathrm{~km}$ from the outer edge of the Great Barrier Reef, is undertaken to investigate the mineral magnetic response to environmental (sea level) changes. Viscous remanent magnetization (VRM) of both multidomain and near-superparamagnetic origin is prevalent and largely obscures the primary remanence, except in isolated high-magnetization zones. The Brunhes/Matuyama boundary cannot be identified, but is expected to be below $120 \mathrm{mbsf}$. The only evidence that exists for a geomagnetic excursion occurs at about 33 mbsf $(\sim 135$ k.y.). Only one-half the cores were oriented, and many suffered from internal rotation about the core axis, caused by coring and/or slicing. The decay of magnetic remanence below the surface layer ( $0-2 \mathrm{mbsf})$ is attributed to sulfate reduction processes.

The magnetic susceptibility $(K)$ record is central for describing and understanding the magnetic properties of the sediments, and their relationship to glacio-eustatic fluctuations in sea level. Three prominent magnetic susceptibility peaks, at about 7, 32, and $64 \mathrm{mbsf}$, are superimposed on a background of smaller susceptibility oscillations. Fluctuations in susceptibility and remanence in the "background" zone are controlled predominantly by variations in the concentration, rather than the composition of ferrimagnetics, with carbonate dilution playing an important role (type-A properties). The sharp susceptibility maxima occur at the start of the marine transgressions following low stands in sea level (high $\delta^{18} \mathrm{O}$, glacial maxima), and are characterized by a stable single-domain remanence, with a significant contribution from ultra-fine, superparamagnetic grains (type-C properties). During the later marine transgression, the susceptibility gradually returns to low values and the remanence is carried by stable single-domain magnetite (type-B properties). The A, B, and C types of sediment have distinctive ARM $/ K$ ratios. Throughout most of the sequence a strong inverse correlation exists between magnetic susceptibility and both $\mathrm{CaCO}_{3}$ and $\delta^{18} \mathrm{O}$ variations. However, in the sharp susceptibility peaks (early transgression), more complex phase relationships are apparent among these parameters. In particular, the $K-\delta^{18} \mathrm{O}$ correlation switches to positive, then reverts to negative during the course of the late transgression, indicating that two distinct mechanisms are responsible for the $K-\delta^{18} \mathrm{O}$ correlation. Lower in the sequence, where sea-levelcontrolled cycles of upward-coarsening sediments, we find that the initial, mud phase of each cycle has been enriched in high-coercivity magnetic material, which is indicative of more oxic conditions. The main magnetic characteristics of the sediments are thought to reflect sea-level-controlled variations in the sediment source regions and related run-off conditions. Some preliminary evidence is seen that biogenic magnetite may play a significant role in the magnetization of these sediments.
\end{abstract}

\section{INTRODUCTION}

Leg 133 Site 820 is located on the upper slope of the northeast Australian continental margin, approximately $10 \mathrm{~km}$ from the outer edge of the Great Barrier Reef and $50 \mathrm{~km}$ from the Australian shoreline (Fig. 1). The site was chosen primarily to provide a high-resolution record of the sediment response to fluctuations in sea level during the Quaternary. Paleomagnetic work was undertaken with two objectives: (1) to provide a reversal chronology and (2) to investigate the relationship between changes in mineral magnetic properties and environmental factors, particularly glacio-eustatic variations in sea level. A detailed record of $\delta^{18} \mathrm{O}$ variations (Peerdeman et al., this volume) and a good $\mathrm{CaCO}_{3}$ record (Feary, this volume) are available against which the magnetic properties of the sediments can be compared.

The relationship between changes in the environment (often climate) and magnetic properties of sediments (often grain-size variations) is treated most simply as a "forward" problem: the object being to demonstrate that magnetic parameters correlate with environmentally sensitive factors, such as oxygen isotope ratios. It is always interesting to find such correlations, for example, in Chinese loesses (Kukla et al., 1988). However, given the sensitivity of magnetic parameters to depositional and alteration conditions, it would be

\footnotetext{
${ }^{1}$ McKenzie, J.A., Davies, P.J., Palmer-Julson, A., et al., 1993. Proc, ODP, Sci. Results, 133: College Station, TX (Ocean Drilling Program).

${ }^{2}$ Australian Geological Survey Organisation, P.O. Box 378, Canberra, ACT 2601. Australia.

${ }^{3}$ Present address: CSIRO Division of Exploration Geoscience, North Ryde, NSW 2113, Australia.

${ }_{4}^{4}$ Research School of Earth Sciences, Australian National University, Canberra, ACT 2601, Australia.
}

surprising if such correlations did not exist in a wide variety of situations. More enlightening is the "inverse" problem: how can the magnetic record be used to provide new information about environmental change? Like most geophysical inverse problems, this is much more difficult to deal with, and seldom yields unique answers.

In the ensuing discussion, the terms "magnetite" and "hematite" are used often in a generic sense to denote mineral assemblages that have magnetite- or hematite-type responses to the rock property tests performed at room temperature. For example, many of the measurements performed do not distinguish between ferrimagnetics such as magnetite, maghemite, and pyrrhotite (all saturate at low fields), or between hematite and goethite (both have high coercivities). Detailed magnetic mineral analysis and high-temperature thermomagnetic work has not yet been undertaken.

Conversions from the cgs units used in this paper to $S I$ units are as follows: Magnetic field strength $(H): 1$ oersted $(\mathrm{Oe})$ corresponds to a flux density of 0.1 millitesla (mT) in a vacuum; intensity of magnetization: 1 microgauss $(\mu \mathrm{G})=10^{-3} \mathrm{~A} \mathrm{~m}^{-1}$; volume susceptibility $K): 1 \mathrm{G} \mathrm{Oe}^{-1}=1 / 4 \pi$ SI units (dimensionless).

\section{CORE RECOVERY AND SAMPLING}

Hole $820 \mathrm{~A}$ was drilled in $278.0 \mathrm{~m}$ of water at $16^{\circ} 38.221^{\prime} \mathrm{S}$, $146^{\circ} 18.229^{\prime} \mathrm{S}$. A hydraulic piston corer (APC) was used for the first 15 cores and penetrated from 0 to 140.2 mbsf ( $102.5 \%$ recovery), followed by two cores drilled with a vibrapercussive corer (VPC) that penetrated from 140.2 to 144.2 mbsf (49.5\% recovery). Hole $820 \mathrm{~B}$ was drilled adjacent to Hole $820 \mathrm{~A}$ in $279.0 \mathrm{~m}$ of water at $16^{\circ} 38.219^{\prime} \mathrm{S}$, $146^{\circ} 18.218^{\prime} \mathrm{E}$. The APC was used for the first 17 cores from 0 to 160.2 mbsf (100.7\% recovery), followed by rotary (XCB) coring from 


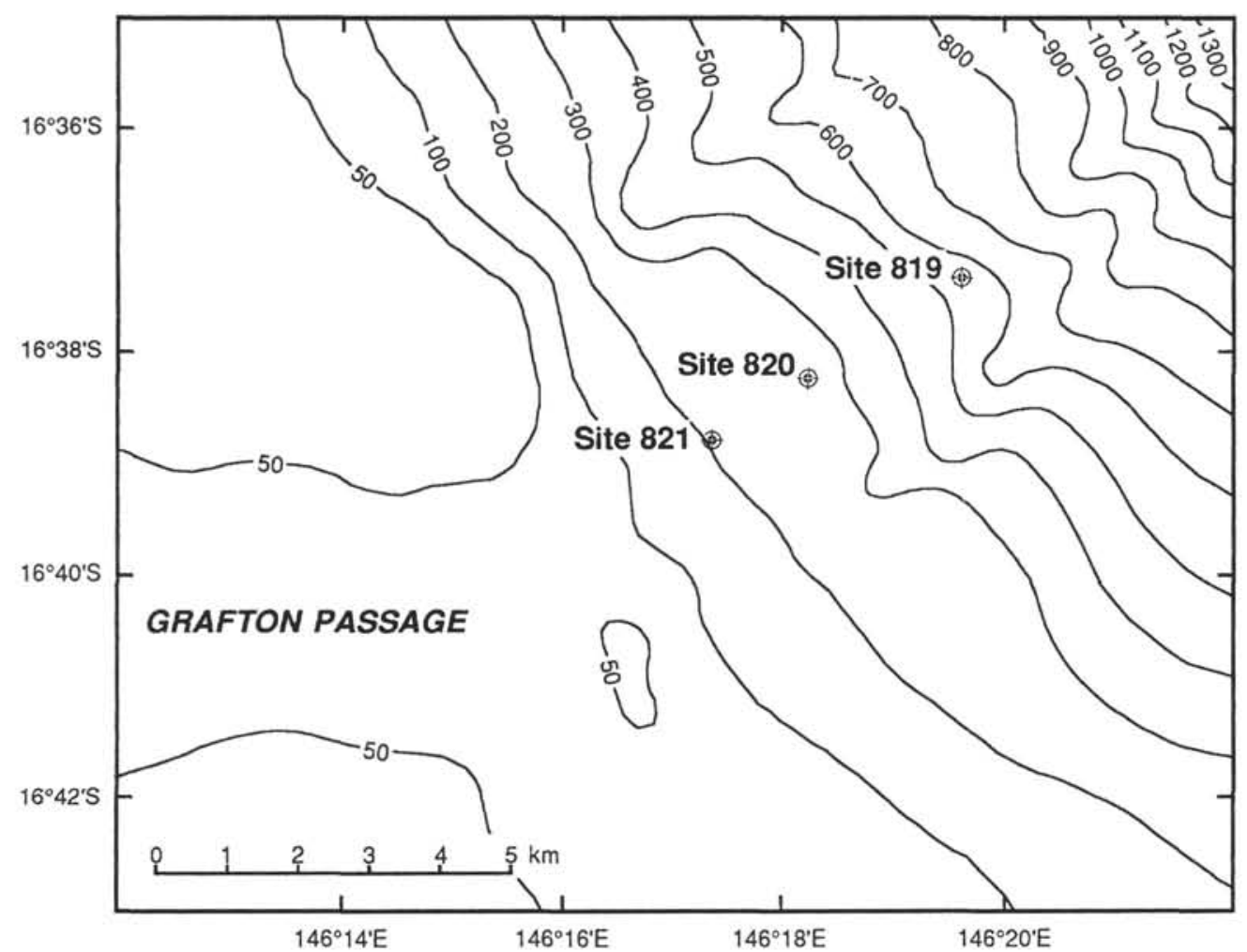

Figure 1. Location of Site 820 with bathymetry in meters. Site 820 is approximately $10 \mathrm{~km}$ from the outer edge of the Great Barrier Reef and $50 \mathrm{~km}$ from the Australian shoreline. Locations of Sites 819 and 821 are also shown. Site 822 is off the map approximately $25 \mathrm{~km}$ to the north.

160.2 to $400.0 \mathrm{mbsf}$ ( $68.2 \%$ recovery). An irregularity in core recovery occurred in Hole $820 \mathrm{~B}$ at the start of XCB drilling: Core $18 \mathrm{X}$ has been assigned $189 \%$ recovery. This results in overlap with Core $19 \mathrm{X}$, which is apparent in plots of the data. Azimuthal orientation information was available for half of the nonrotary cores: $9 \mathrm{H}$ to $16 \mathrm{~V}$ from Hole $820 \mathrm{~A}$ and Cores $4 \mathrm{H}$ to $6 \mathrm{H}$ and $12 \mathrm{H}$ to $17 \mathrm{H}$ from Hole $820 \mathrm{~B}$.

Hole $820 \mathrm{~A}$ was sampled on board the ship at 20 -cm intervals $(621$ samples) and Hole $820 \mathrm{~B}$ was sampled at 4-cm intervals ( 735 samples). A further six samples from Hole $820 \mathrm{~A}$ and 39 from Hole $820 \mathrm{~B}$ were collected in March 1991. In the rotary-drilled cores, samples were collected from the least-disturbed, apparently nonrotated portions of sediment. The sample nomenclature used here (e.g., 820A, 03-5-125) refers to the base of the sampling interval (i.e., Core 3, Section 5, 125 $\mathrm{cm}$, from the top of the section). Depths to the center of each paleomagnetic specimen are assumed to be $1 \mathrm{~cm}$ above the bottom of the sampling interval.

\section{SHIPBOARD MEASUREMENTS}

Shipboard whole-core measurements of natural remanent magnetization (NRM), magnetic remanence after alternating-field (AF) cleaning at 150-Oe peak field, and initial low-field magnetic susceptibility per unit volume $(K)$ were performed at 10 -cm intervals on the archive halves of cores by the Shipboard Scientific Party. Remanence measurements for Hole 820B were discontinued after Core 35X. Results were reported by the Shipboard Scientific Party (1991). A normal polarity record of acceptable quality was observed down to $100 \mathrm{mbsf}$. Below this level, directional data were extremely erratic (attributed to drilling disturbance) and failed to resolve any reversal boundaries. The sediments were weakly magnetized (typically $<1 \mu \mathrm{G}$ in the upper $140 \mathrm{~m}$ and between 0.1 and $10 \mu \mathrm{G}$ below $140 \mathrm{~m}$ ), with high values at the surface, and three prominent square-topped peaks at about 5, 32, and 64 mbsf. The susceptibility record was observed to be similar in character to the remanence record. The Shipboard Scientific Party (1991) pointed out that "geochemical data, particularly a strong gradient in sulfate near the top of the core, suggest strong reducing conditions that may have destroyed much of the original magnetic minerals." The nannofossil data suggest that the Brunhes/ Matuyama boundary should lie below 110 mbsf.

\section{LABORATORY MEASUREMENTS}

NRM and initial low-field magnetic susceptibility measurements were performed for all specimens collected. Complete step-wise AF demagnetization was conducted on 72 specimens distributed through the sequence. Viscous remanent magnetization (VRM) acquisition tests were done on 95 selected specimens from Holes 820A and 820B before any treatment was applied, and also on 38 specimens from Hole $820 \mathrm{~A}$ after prior AF demagnetization. The bulk of the collection was then AF demagnetized at $100 \mathrm{Oe}$, and some again at $300 \mathrm{Oe}$. Measurements were performed on alternate specimens of anhysteretic remanent magnetization (ARM), using $0.4 \mathrm{Oe} \mathrm{DC}$ field and $1000 \mathrm{Oe}$ $\mathrm{AF}$, and near-saturation isothermal remanent magnetization (IRM) using a DC field of $5000 \mathrm{Oe}$. The IRM measurements were later repeated using a reverse field of $3000 \mathrm{Oe}$. To characterize further the magnetic nature and domain state of the sediments, the following magnetic properties of selected specimens were examined: frequency dependence of susceptibility, low-temperature (liquid nitrogen) susceptibility and IRM response, Lowrie Fuller test, IRM acquisition, and coercivity of remanence. Finally, four specimens were examined under a transmission electron microscope (TEM) to identify possible bacterial magnetite. The most detailed magnetic measurements performed were on Hole $820 \mathrm{~A}$, with relatively little attention being paid to the corresponding section in Hole $820 \mathrm{~B}$. Thus, the magnetic record 
for the whole sequence at Site 820 is best represented by Hole $820 \mathrm{~A}$ (0-140 mbsf), together with Hole 820B (140-380 mbsf).

\section{MAGNETIC SUSCEPTIBILITY}

Low-field magnetic susceptibilities per unit volume were measured in all samples of wet sediment. The record obtained in the upper $80 \mathrm{mbsf}$ of Hole $820 \mathrm{~A}$ is illustrated in Figure 2 and the complete record is shown in Figure 9A. A linear susceptibility scale has been chosen for Figure 2 to emphasize the susceptibility peaks. The records from Holes $820 \mathrm{~A}$ and $820 \mathrm{~B}$ are closely correlated (see below) and are combined to produce Figure 9A. The subsample records and the shipboard whole-core data are in excellent agreement.

Susceptibilities are generally low throughout most of the sequence, with the majority of specimens having susceptibilities $<10$ $\mu \mathrm{G} / \mathrm{Oe}^{-1}$ and often $<5 \mu \mathrm{G} / \mathrm{Oe}^{-1}$. Superimposed on this background are three prominent peaks: Peak 1 (3.5-7.5 mbsf in Hole 820A), Peak 2 (29.4-33.5 mbsf in Hole 820A), and Peak 3 (62.4-65.4 mbsf in Hole $820 \mathrm{~A}$ ). Peaks 1 and 2 have susceptibilities of up to 50 $\mu \mathrm{G} / \mathrm{Oe}^{-1}$, and Peak 3 is somewhat smaller, reaching $20 \mu \mathrm{G} \mathrm{Oe}{ }^{-1}$.

The two main peaks share a characteristic morphology: a rapid increase to a sharp narrow maximum, followed by a more gradual relaxation to low background values. Peak 3 is similar, except that the sharp maximum is less prominent. Several smaller, broader peaks occur lower in the sequence (e.g., at 193.5-203 mbsf and 338.5-358 mbsf in Hole 820B). For reasons that will become apparent later, we have adopted the following sediment-type (zonation) classification:

Type $\mathrm{S}=$ surface zone $(\leq 2 \mathrm{mbsf}$ in Hole $820 \mathrm{~A})$,

Type $\mathrm{A}=$ low susceptibility background zone on which the main peaks have been superimposed,

Type $\mathrm{B}=$ relaxation phases following the sharp peaks, and

Type $\mathrm{C}=$ sharp maxima of the main susceptibility peaks.

These have been further subdivided into Zones A1, B1, C1 for the zones down to Peak 1, and so on for Peaks 2 and 3. Below Peak 3, the background is referred to just as Zone A.

\section{INTERHOLE CORRELATION}

As magnetic susceptibilities are generally found to have a log-normal distribution, plotting on a linear scale, as in Figure 2, gives undue prominence to the high values and suppresses variations at low values. When plotted on a logarithmic scale, the low-amplitude fluctuation stand out better and can be used to correlate accurately between Holes $820 \mathrm{~A}$ and $820 \mathrm{~B}$. Depths in the two holes corresponding to the same susceptibility feature are listed in Table 1 . These provide a convenient means of transforming depths in one hole to the other using linear interpolation between corresponding horizons. This is generally accurate to within $20 \mathrm{~cm}$. Units of "A mbsf" and "B mbsf" have been used for the figures to denote which depth scale is being used. The only major differences between recoveries in the two adjacent holes are that the intervals 8.0 to $9.3 \mathrm{mbsf}$ and 36.2 to $38.2 \mathrm{mbsf}$ in Hole $820 \mathrm{~A}$ appear to be missing from $820 \mathrm{~B}$. The high level of agreement can be gauged from the susceptibility plot for 0 to $150 \mathrm{mbsf}$ in Figure $9 \mathrm{~A}$, which combines data from both holes.

\section{NATURAL REMANENCE VRM Tests}

VRMs were tested in 95 untreated specimens by exposing them to the laboratory field $(\sim 0.4 \mathrm{Oe})$ in a known orientation for up to 1000 $\mathrm{hr}$. Specimens were housed in a $\mu$-metal shield for at least $48 \mathrm{hr}$ before the tests began.

Results show that a large, short time-constant VRM is pervasive. For most specimens, the VRM acquired after $1 \mathrm{hr}$ was from $25 \%$ to $50 \%$ (average $30 \%$ ) of the NRM (Fig. 3), and most specimens gained $100 \%$ of their NRM intensity after $300 \mathrm{hr}$. After $1000 \mathrm{hr}$ all specimens exceeded this threshold, apart from those in the high NRM zones. The propensity for VRM acquisition varies little with depth in the back-

Table 1. Corresponding depths between Holes $820 \mathrm{~A}$ and $820 \mathrm{~B}$, based on matching susceptibility features.

\begin{tabular}{|c|c|c|c|}
\hline$\underset{\text { (mbsf) }}{\mathrm{A}}$ & $\underset{(\mathrm{mbsf})}{\text { B }}$ & $\underset{(\mathrm{mbsf})}{\mathrm{A}}$ & $\begin{array}{c}\text { B } \\
\text { (mbsf) }\end{array}$ \\
\hline 0.0 & 0.0 & 53.5 & 52.0 \\
\hline 6.5 & 6.9 & 60.5 & 59.0 \\
\hline 8.0 & 8.3 A missing & 63.5 & 62.0 \\
\hline 9.5 & 8.5 in B & 65.7 & 65.5 \\
\hline 11.0 & 9.9 & 73.5 & 74.5 \\
\hline 12.0 & 11.5 & 79.0 & 79.0 \\
\hline 14.0 & 13.2 & 82.0 & 80.0 \\
\hline 17.8 & 17.3 & 83.7 & 82.0 \\
\hline 18.7 & 18.7 & 86.0 & 84.5 \\
\hline 20.5 & 20.5 & 89.5 & 88.0 \\
\hline 22.0 & 21.6 & 93.8 & 92.0 \\
\hline 27.0 & 26.7 & 104.5 & 105.0 \\
\hline 29.5 & 28.0 & 108.0 & 106.5 \\
\hline 32.5 & 31.5 & 113.5 & 112.0 \\
\hline 34.0 & 33.4 & 120.0 & 118.0 \\
\hline 35.5 & 35.0 & 124.0 & 121.8 \\
\hline 36.2 & 36.0 A missing & 125.0 & 122.3 \\
\hline 38.5 & 36.5 in $B$ & 131.0 & 129.5 \\
\hline 40.0 & 38.0 & 131.5 & 130.0 \\
\hline 42.5 & 40.9 & 137.5 & 135.2 \\
\hline 43.5 & 42.0 & 139.0 & 136.6 \\
\hline 44.0 & 42.8 & 140.0 & 137.4 \\
\hline 48.0 & 46.5 & 142.0 & 140.0 \\
\hline 50.5 & 49.0 & 144.0 & 142.0 \\
\hline 52.3 & 51.0 & & \\
\hline
\end{tabular}

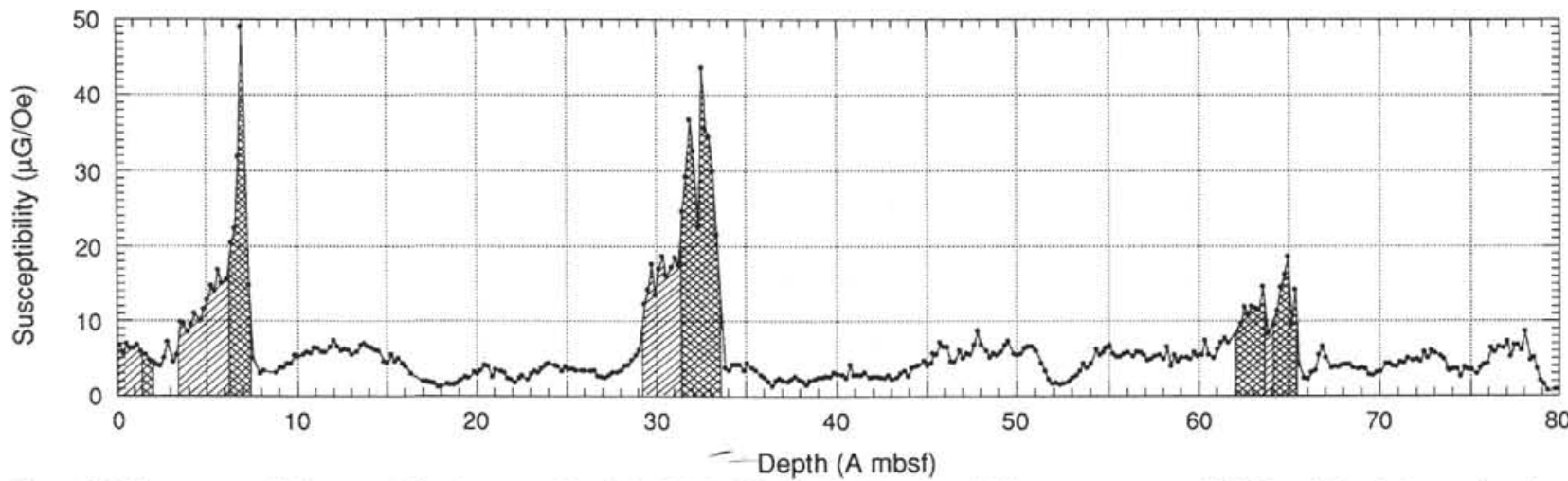

Figure 2. Volume susceptibility record for the upper $80 \mathrm{mbsf}$ of Hole $820 \mathrm{~A}$. The high susceptibility zones at around 5,32 , and $64 \mathrm{mbsf}$ are referred to in the text as Peaks 1,2, and 3, respectively. Susceptibility is plotted on a linear scale to emphasize the peaks. The depth scale for Hole $820 \mathrm{~A}$ is labeled as "A (mbsf)," as distinct from "B (mbsf)" that is used to denote the depth scale for Hole 820B. Sediment zones, as defined by characteristic ARM/K ratios (see text), are unshaded for type-A, hachured for type-B, and cross-hachured for type-C. 
ground zones, except for the two highly viscous samples in Hole $820 \mathrm{~B}$ at 169.96 and 261.03 mbsf.

The various zones defined for the susceptibility record each have distinctive VRM characteristics. Recovery phase (type-B) sediments show the least VRM gain (typically 5\%-7\% after $1 \mathrm{hr}$ and usually $<15 \%$ after $1000 \mathrm{hr}$ ). Samples from the surface zone (type-S) are slightly more viscous than those in the B zones $(6 \%-10 \%$ after $1 \mathrm{hr}$ and $~ 30 \%$ after $1000 \mathrm{hr}$ ). In the $\mathrm{C} 1$ and $\mathrm{C} 2$ zones, VRM gains were only marginally less than for background (type A) samples, and Peak 3 is much more akin to the $\mathrm{B} 1$ and $\mathrm{B} 2$ zones than to the $\mathrm{C} 1$ and $\mathrm{C} 2$ zones.

A set of 38 specimens was AF demagnetized at 300 Oe before the VRM test. These specimens generally exhibited very high VRM gain ( $80 \%-400 \%$ of the NRM in the first hour-Fig. 3, squares and dashed lines). Specimens from Peak 3 ( 64 mbsf) showed lower VRM gains, similar to those that were not initially demagnetized, whereas specimens from the other peaks gained $\sim 100 \%$. Tivey and Johnson (1984) and Potter and Stephenson (1990) discussed the effect of AF demagnetization on rock magnetic properties and also noted that much larger VRMs are acquired after initial AF demagnetization of samples containing multidomain (MD) magnetite.

Thus, it appears that, except in the upper zone and in the high magnetization zones, VRM may account for nearly all of the natural remanence of these sediments. A MD origin of the VRM is the simplest explanation, possibly with a contribution from ultrafine grains near the single-domain (SD)-superparamagnetic (SP) size threshold. A contribution from low-stability magnetic minerals, such as some iron monosulfides, remains a further possibility, but has not yet been investigated.

\section{NRM Intensity}

The NRM intensity record (Fig. 4) looks similar to the susceptibility record, being characterized by relatively high NRM values in the top $2 \mathrm{~m}$ (Zone S), two similar peaks at about 6 (Peak 1) and 32 (Peak 2) mbsf, and a somewhat weaker peak (Peak 3) at about 64 mbsf. These peaks are superimposed on a relatively uniform, weakly magnetized background (Zone A), with NRM typically $\sim 0.1$ to $1 \mu \mathrm{G}$.

The subsample data are in good agreement between the overlapping parts of Holes $820 \mathrm{~A}$ and $820 \mathrm{~B}$. Generally, good agreement also is found with the shipboard whole-core results.

However, the subsamples have NRM values that are typically lower than the whole-core measurements by a factor of about two. Part of this may be a calibration problem, although one commonly finds that the NRM of fresh sediments decays with time. The fact that some zones do exist where the subsample and whole-core intensities agree closely (e.g., 45-55 mbsf in Hole $820 \mathrm{~A}$ and in the three main peaks) suggests that the latter may be the case, and may be compounded by VRM effects.

The high NRM intensity in the uppermost $2 \mathrm{~m}$ does not have a susceptibility counterpart, which suggests that it has a different origin from the other three main peaks. It is probably not climatically related, but is caused by a concentration of SD primary detrital iron oxides in the uppermost sediments. A significant fraction of these become preferentially removed by progressive sulfate reduction as the sediment ages (Karlin and Levi, 1983). Such a mechanism is suggested in the Initial Reports volume (Shipboard Scientific Party, 1991), where attention was drawn to the steep sulfate gradient near the top of the hole as indicative of strongly reducing conditions. The observed prominent decay of NRM with increasing depth, with little corresponding change in susceptibility, is evidence that the very fine-grained magnetic fraction responsible for carrying the NRM is most vulnerable to sulfate reduction. The reduction process is expected to preferentially remove the very fine-grained particles and, initially, shift the grain-size spectrum in the MD direction. In the terminal stages of sulfate reduction, before all the primary iron oxides are finally removed, a finer grain-size bias may be established.

\section{Progressive AF Demagnetization}

Progressive AF demagnetization was completed in 72 pilot specimens distributed throughout the sequence. Demagnetization steps attempted were usually $0,25,50,100,150,200,300,400,500,600$, and sometimes $700 \mathrm{Oe}$, although measurements at the higher AF values were not always possible. A large, soft (viscous) component of magnetization, often parallel to the harder directions, is common throughout the sequence, except at the surface and in the peak intensity zones. The upper $7 \mathrm{~m}$ of Hole $820 \mathrm{~A}$ is characterized by a relatively stable single component of magnetization with inclinations closer to the present-day inclination, $-45^{\circ}$, than to the axial dipole value, $-31^{\circ}$ (Fig. 5A). Peaks 2 and 3 also carry a stable, single normal component of magnetization, but inclinations are closer to the axial dipole value (Fig. 5B). Lower down in Hole 820A, outside the high intensity zones, we see a more complicated behavior, normal endpoint directions, often with poorer stability (Fig. 5C), and commonly with a large soft viscous overprint (Fig. 5D). A gradual deterioration of stability occurs with increasing depth, particularly below about 125 mbsf. A few specimens in Hole $820 \mathrm{~B}$ were reversed with a soft normal overprint (Fig. 5E), but many of those that showed signs of reversals only switched from normal to reversed inclinations at high demagnetizing fields, without achieving stable end-point directions (Fig. 5F). Thus, demagnetization could often not be continued far enough to test for the relicts of a very hard, weak primary magnetization.

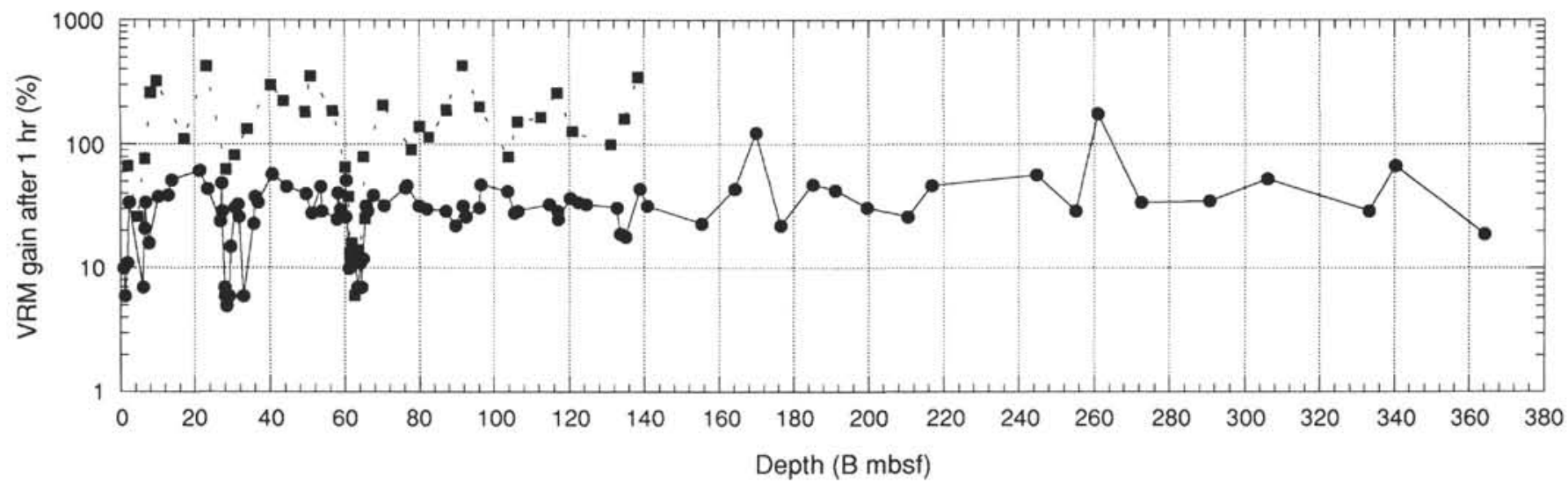

Figure 3. VRM gain after $1 \mathrm{hr}$ in an applied field of $0.4 \mathrm{Oe}$, combined data for Holes 820A and 820B. The VRM gain is expressed as the percentage vector difference of remanence with respect to initial NRM. The circles joined by solid lines are for no initial treatment; squares joined by dashed lines are for specimens initially AF demagnetized at 300 Oe. All data have been plotted on the depth scale for Hole $820 \mathrm{~B}$. 
A
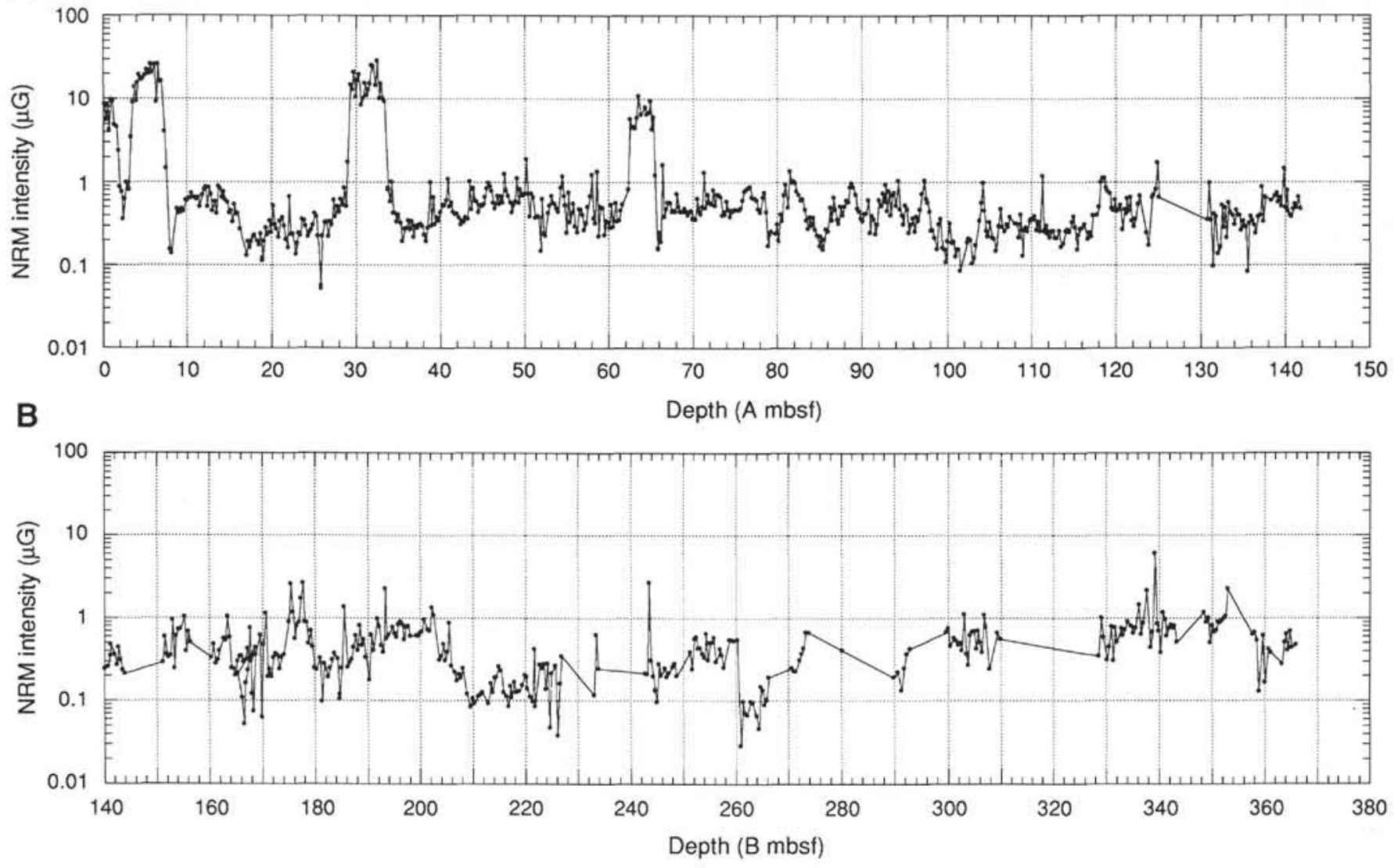

Figure 4. Subsample NRM intensity records for below 140 mbsf. A. Hole $820 \mathrm{~A}$. B. Hole $820 \mathrm{~B}$. The overlap in Hole $820 \mathrm{~B}$ at about 165.2 to $169.3 \mathrm{mbsf}$ was caused by the assigned $189 \%$ recovery for Core $18 \mathrm{X}$.

Median destructive field (MDF) values have been plotted in Figure 6. Samples from the top $7 \mathrm{~m}$ of the sequence have the highest MDF values, usually $>250$ Oe. The high magnetization zones have MDFs that range up to about $300 \mathrm{Oe}$. Otherwise, MDF tends to decrease with depth, with values typically less than $100 \mathrm{Oe}$ (except at about $89 \mathrm{mbsf}$ and between $130-135 \mathrm{mbsf}$ ). MDF values are particularly low below about 140 mbsf. These very low values of MDF result from the ubiquitous large, soft, magnetic component in all but the high magnetization zones.

As progressive demagnetization of the whole collection was neither practical, nor likely to produce much additional information, most of the remaining specimens were $\mathrm{AF}$ cleaned at 100 and some again at 300 Oe. Demagnetization at the higher field generally reduced the intensity to values that were difficult to measure (at the few $\times 10^{-8} \mathrm{G}$ level) and did not change the record sufficiently to influence the interpretation of the results.

\section{Magnetic Inclination}

Inclination records for both holes after magnetic cleaning are shown in Figure 7, both for subsample (Figs. 7B, 7C) and whole-core (Figs. 7A, 7D) data. Note that whole-core inclination data plotted by the Shipboard Scientific Party (1991) were given a positive sign for normal polarity, such is the vanity of Northern Hemisphericans. To facilitate comparisons, the data for Hole 820A have been transformed to a Hole $820 \mathrm{~B}$-depth scale, based on a match between the two susceptibility records (discussed earlier). The tramlines on the plots denote the axial dipole inclinations $\left( \pm 31^{\circ}\right)$. Inclinations are scattered, particularly below $140 \mathrm{mbsf}$, which suggests that rotary XCB-coring produced much more disturbance than was initially apparent from visual inspection of the cores.

Directions in the upper $120 \mathrm{~m}$ are centered about the axial dipole inclination, except in the whole-core record for Hole 820A, in which they are generally steeper. No corresponding steepening is seen for the Hole $820 \mathrm{~B}$ whole-core record. This is surprising and may be due to a drilling-induced remanence that was not picked up in the subsamples. Through the top $10 \mathrm{~m}$ (possibly $30 \mathrm{~m}$ ) of subsample data for Hole $820 \mathrm{~A}$, a steepening inclination trend can be seen that suggests that directions have been influenced by the steep present-day inclination (about $-45^{\circ}$ ). However, neither the subsample data for Hole $820 \mathrm{~B}$, nor the whole-core data support this argument (although a steepening trend is apparent from 20 to 7 mbsf in the Hole $820 \mathrm{~B}$ subsample data). Given the level of scatter, generally good agreement exists between the Hole $820 \mathrm{~A}$ and $820 \mathrm{~B}$ records, and some of the broad trends in inclination in the top $120 \mathrm{~m}$ are reproduced in the two sections (see, for example, the steep inclinations at 90-100 mbsf), possibly reflecting long-period secular variation.

The Brunhes/Matuyama (B/M) boundary is not resolved, and no intervals of reversed polarity lower in the sequence can be identified with any certainty. The B/M boundary is expected at about 120 to 130 mbsf, based on nannofossil and oxygen isotope data. An increase in the number of intermediate directions is apparent below about 120 mbsf (=118 mbsf in Hole $820 \mathrm{~A})$, which might be taken, in desperation, as some indication of a heavily overprinted, reversed, primary magnetization. In a few zones, a dominance of intermediate directions with reverse bias is seen, but no reversals that are sufficiently welldefined to provide useful chronological information. The agreement between the subsample and whole-core data in these zones is gener- 
A
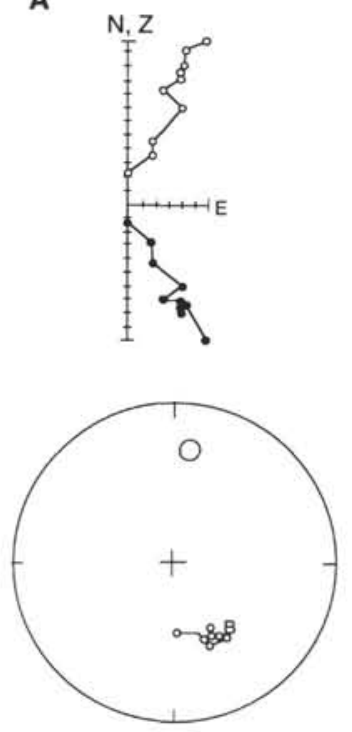

D
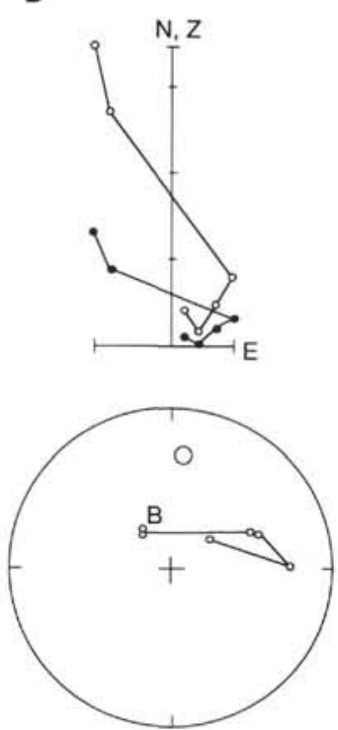

B
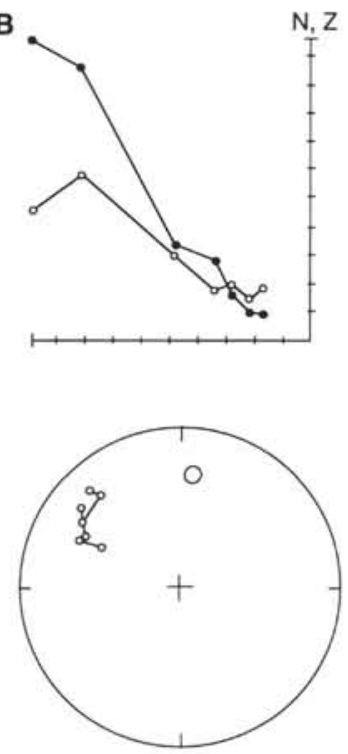

E
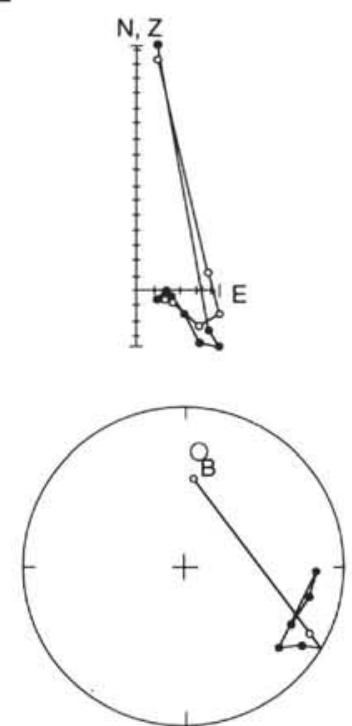

C
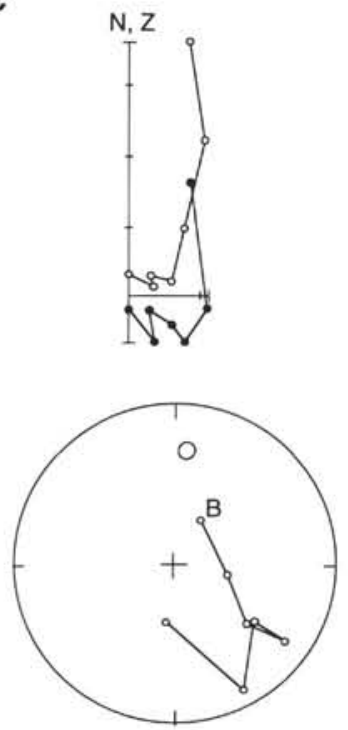

$\mathbf{F}$
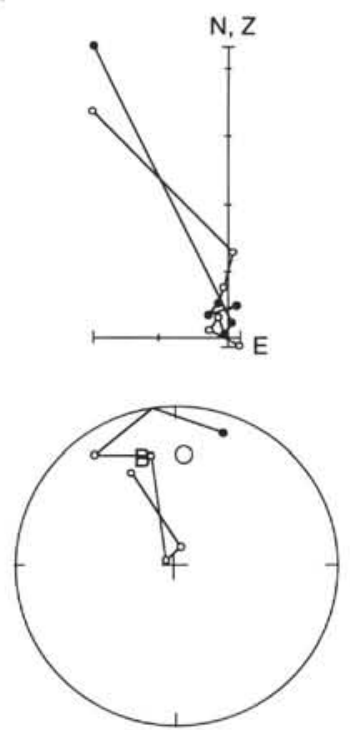

Figure 5. Progressive AF demagnetization plots. A. Hole 820A, 4.67 mbsf. B. Hole 820A, 31.66 mbsf. C. Hole 820A, 93.47 mbsf. D. Hole 820A, 136.86 mbsf. E. Hole 820B, 353.06 mbsf. F. Hole 820B, 255.86 mbsf. For the orthogonal plots, open symbols are for inclination and solid symbols for declination. On the stereoplots, the large open circle has the axial dipole inclination $\left(-31^{\circ}\right)$ and present-day site declination $\left(7.5^{\circ} \mathrm{E}\right) ; \mathrm{B}$ denotes the first step. Declinations are in sample coordinates (unoriented).

ally poor, and the shift toward more positive inclinations below 140 mbsf in the Hole $820 \mathrm{~B}$ whole-core record is not seen in the corresponding subsample record.

A few reversed spikes in the "normal" data can be seen above 120 mbsf, but only the one at about $33 \mathrm{mbsf}$ is reproduced in the subsample data from both holes. A well-defined zone of anomalous inclinations occurs at this depth in the whole-core data for Hole $820 \mathrm{~B}$, but only scant evidence of this is seen in Hole $820 \mathrm{~A}$. However, the possibility remains that the sediments are recording an excursion of the geomagnetic field. We note that the feature coincides with the high intensity Peak 2 and with low sea level (discussed below).

\section{Magnetic Declination}

The AF-cleaned declination record is illustrated for Hole $820 \mathrm{~B}$ (upper $140 \mathrm{mbsf}$ ) in Figure 8. The record for Hole 820A is similar, but with more outliers, particularly at the top of each core section. Lower in the Hole $820 \mathrm{~B}$ sequence (rotary drilled), the declination record is too scattered to be intelligible. The oriented cores $(-4 \mathrm{H}-6 \mathrm{H}$ and $-12 \mathrm{H}-16 \mathrm{H})$ are corrected to the measured azimuths. The remaining cores have been rotated so that the interquartile mean declination is zero for each core. The record does not shed any further light on the possible location of the B/M boundary. A single-point spike appears at $32 \mathrm{mbsf}$ in the Hole $820 \mathrm{~A}$ record, but no evidence is found for an excursion at this depth in Hole 820B.

It appears that the shipboard core orientation system has problems. First, it is clear that declinations for adjacent oriented cores do not match up and that orientations may be out by up to $60^{\circ}$ or more (e.g., Core $-5 \mathrm{H})$. Second, a trend in declination data from each core can be seen, which suggests that most cores are twisted relative to the core liner, typically by 10 to $20^{\circ}$ (core torqued counter-clockwise relative to the liner when viewed into the ends of the core). 


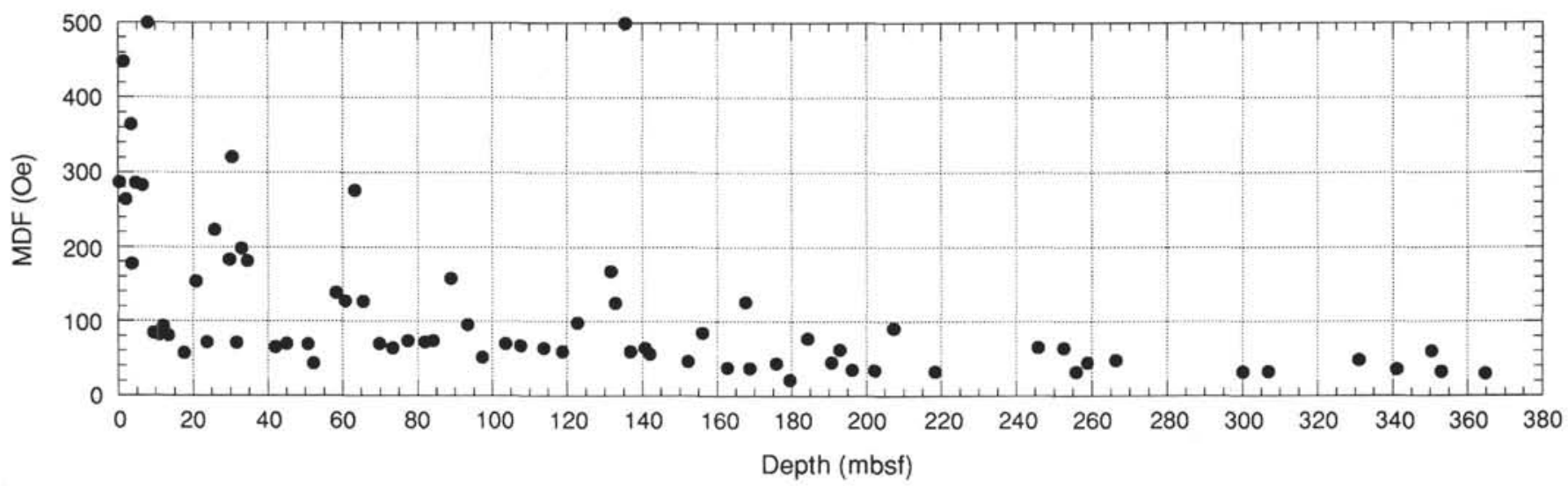

Figure 6. Median destructive field of NRM for Holes $820 \mathrm{~A}$ and $820 \mathrm{~B}$ below $140 \mathrm{mbsf}$. The two specimens plotted at the 500 Oe upper limit failed to reach the half-intensity level during AF demagnetization.

\section{$\mathrm{CaCO}_{3}$ VARIATIONS}

The downcore record of calcium carbonate variations is of interest for several reasons: (1) it has climatic/sea-level implications, (2) it may reflect fine-scale variations in sedimentation rate, and (3) dilution by $\mathrm{CaCO}_{3}$ can have a marked effect on the magnetic record when carbonate contents are high (Barton and Bloemendal, 1985). A detailed $\mathrm{CaCO}_{3}$ record for Hole $820 \mathrm{~A}$ is available from the shipboard data (Shipboard Scientific Party, 1991, Table 4) and from measurements performed at the Australian Geological Survey Organisation (Feary, this volume). These two data sets agree within a few percent. Carbonate contents are expressed as weight-percent (i.e., $100 \pm$ weight of calcium carbonate/weight of dry sediment).

A remarkable one-to-one inverse correlation is seen between variations in magnetic susceptibility and total calcium carbonate content (Figs. 9A and 9B), which is further demonstrated in Figure 10. Note that susceptibility has been plotted on a logarithmic scale, which is the appropriate scale to choose, given that susceptibility is log-normally distributed in natural environments. (If the same plot is reproduced with a linear susceptibility scale, the distribution of points has a distinct curvature.)

A careful examination of Figure 9 shows that at susceptibility Peak 2 the carbonate minimum ( $\sim 31 \mathrm{mbsf})$ occurs at the transition from the sharp susceptibility maximum (Zone C) to the succeeding recovery phase (Zone B). The same is true for Peak 3 ( $63 \mathrm{mbsf}$ ). Within each of these two sharp susceptibility maxima, the carbonate contents have intermediate values. The maximum of susceptibility Peak 1 behaves differently and appears to coincide exactly with a carbonate minimum. However, a more detailed analysis of the upper $10 \mathrm{~m}$ of the sequence by Peerdeman and Davies (this volume) shows that the carbonate peak comes slightly before the susceptibility maximum (i.e., the reverse of the situation for Peaks 2 and 3). A detailed investigation of the nature and significance of these differences is beyond the scope of this study.

The correlation between susceptibility and $\mathrm{CaCO}_{3}$ poses the obvious question: can the observed susceptibility variations be explained entirely by varying carbonate dilution of a constant influx of magnetic material? Siliceous contents are sufficiently low that dilution by siliceous material can be ignored. To test the hypothesis, the effect of carbonate dilution was removed by calculating the volume susceptibility of the dry noncarbonate fraction $\left(K_{n c}\right)$. In terms of the index parameters published in the Initial Reports volume, a simple calculation shows that the volume susceptibility of dry sediment $\left(K_{\mathrm{s}}\right)$ is given by:

$$
K_{s}=K(R+1)-K_{w} R .
$$

It follows that

$$
K_{n c}=\left(K_{s}-A K_{\mathrm{c}}\right) /(1-A)
$$

where $A=C \rho_{g} \rho_{c}$

and

$C$ = fraction by weight of $\mathrm{CaCO}_{3}\left(=\mathrm{wt} \% \mathrm{CaCO}_{3} / 100\right)$,

$K=$ volume susceptibility of wet sediment $\left(\mu \mathrm{G} \mathrm{Oe}^{-1}\right)$,

$K_{c}=$ volume susceptibility of $\mathrm{CaCO}_{3}\left(=-1.08 \mu \mathrm{G} \mathrm{Oe}^{-1}\right)$,

$K_{w}=$ volume susceptibility of seawater $\left(=-0.731 \mu \mathrm{G} \mathrm{Oe}^{-1}\right)$,

$\rho_{g}=$ grain density (weight of dry sediment/volume of dry sediment, $\mathrm{g} \mathrm{cm}^{+3}$ ),

$\rho_{c}=$ density of $\mathrm{CaCO}_{3}\left(=2.82 \mathrm{~g} \mathrm{~cm}^{-3}\right)$, and

$R=$ void ratio (volume of seawater/volume of dry sediment).

Carbonate data and index properties were interpolated linearly to obtain values at the same depths as the paleomagnetic samples. The downcore variation of $K_{n c}$ is plotted in Figure 9C. Although the amplitude of the fluctuations is noticeably less than for $K$ (except for the peak zones), a significant variation can still be seen. Hence, the simple carbonate dilution model does not fully account for the observations.

\section{Q-RATIO}

Background values of the modified Koenigsberger ratio $(Q=$ $\mathrm{NRM} / K$ ) are low, typically $<0.2 \mathrm{Oe}$, but reach high values in the surface zone and in the three prominent peaks (Fig. 11). Q-ratios in Peaks 1 and 2 differ in morphology from the susceptibility peaks, with higher $\mathrm{Q}$ values in the $\mathrm{B}$ zones than in the $\mathrm{C}$ zones. This is consistent with the greater magnetic stability of type-B sediments. Note that the center of Peak 3 has higher $Q$ values than the margins. The low background Q-ratios are consistent with poor magnetic stability throughout most of the sequence. In environments such as this, such low values can be attributed to the presence of MD or superparamagnetic magnetite grains, both of which have a high susceptibility relative to their remanence carrying capacity.

Q-ratios for a few selected samples are listed in Table 2. The highest $\mathrm{Q}$ values occur in the surface zone and in the most recent recovery phase, $\mathrm{B} 1$. B2 has lower $\mathrm{Q}$ values than $\mathrm{B} 1$. $\mathrm{C} 1$ and $\mathrm{C} 2$ have noticeably lower Q values than the B zone. Peak 3 has a Q-ratio more like type-B than type- $\mathrm{C}$ samples. The low $\mathrm{Q}$ values are confined to the background zone $\mathrm{A}$.

\section{FREQUENCY DEPENDENCE OF SUSCEPTIBILITY}

Additional insight into the contrast between types- $\mathrm{B}$ and $-\mathrm{C}$ sediments comes from measurements of susceptibility at low $(0.47 \mathrm{kHz})$ 
A

Hole $820 \mathrm{~B}$ whole-core

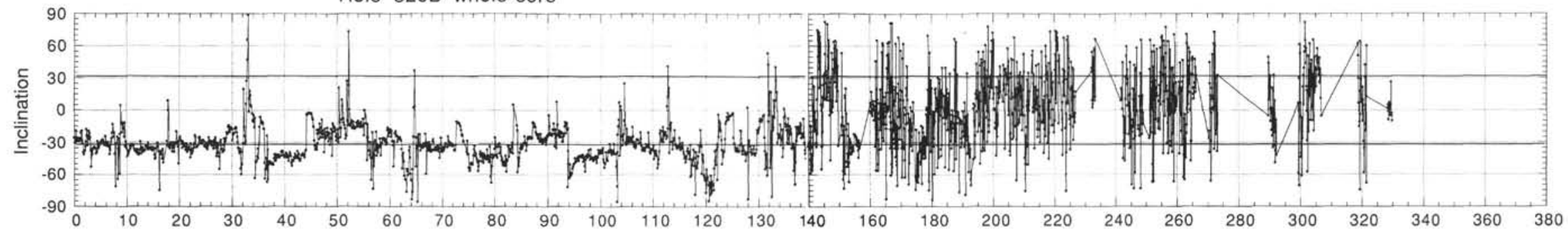

B

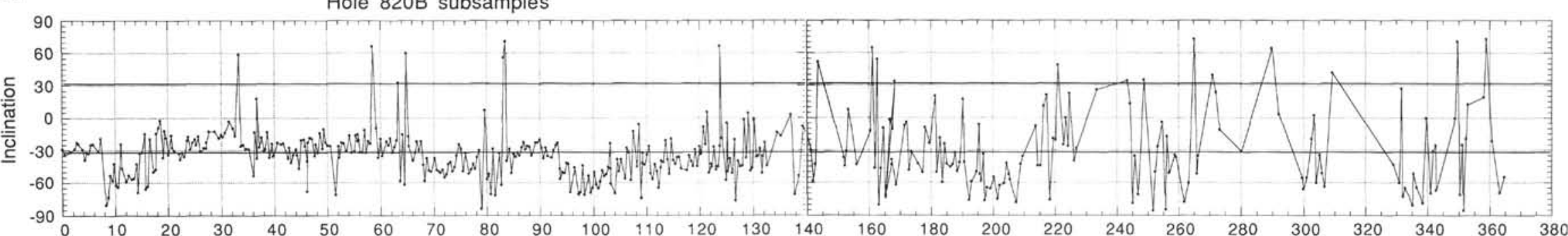

C

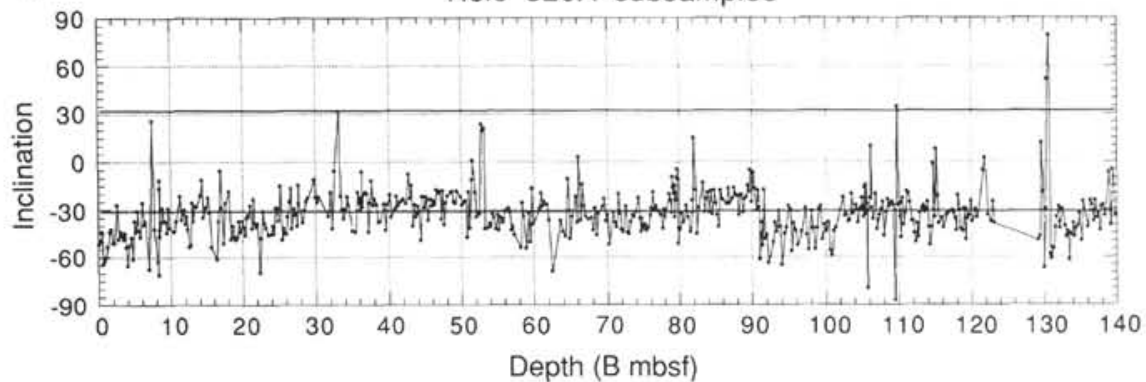

D

Hole 820A whole-core

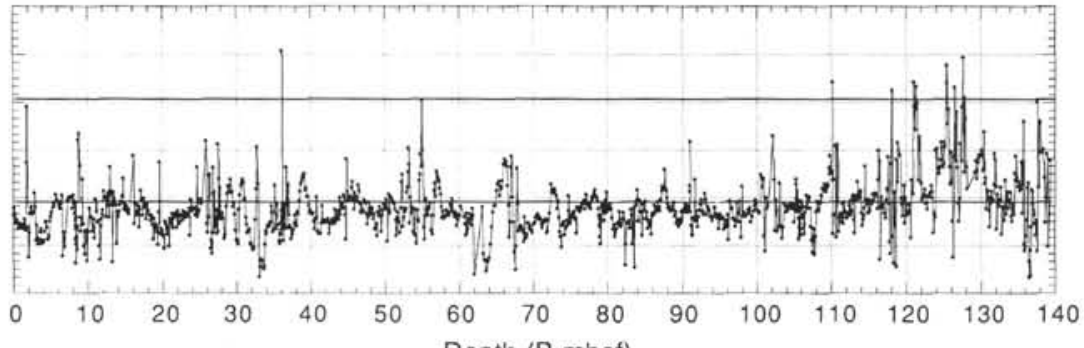

Figure 7. Magnetic inclination after AF magnetic cleaning for (A) Hole 820B, whole-core shipboard data, cleaned at 150 Oe; (B) Hole $820 \mathrm{~B}$ subsamples, cleaned at 100 or 300 Oe; (C) Hole $820 \mathrm{~A}$ subsamples, cleaned at 100 or $300 \mathrm{Oe}$; (D) Hole $820 \mathrm{~A}$, whole-core shipboard data, cleaned at $150 \mathrm{Oe}$. Records for Hole $820 \mathrm{~A}$ have been plotted on the equivalent depth scale for Hole $820 \mathrm{~B}$ (based on matching susceptibility features and linear interpolation). The tramlines are the geocentric axial dipole directions for reversed and normal fields $\left( \pm 31^{\circ}\right.$, respectively). Note the change of depth scale at $140 \mathrm{mbsf}$. 


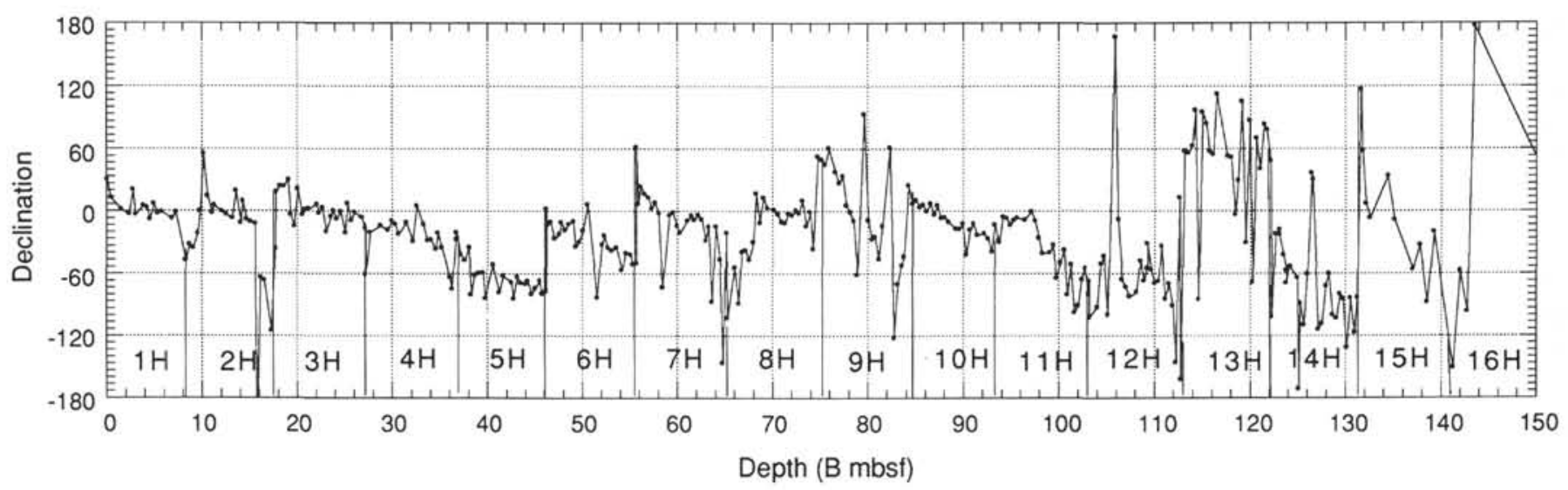

Figure 8. Subsample declination record for Hole $820 \mathrm{~B}$, after AF cleaning. Cores are denoted by $1 \mathrm{H}, 2 \mathrm{H}$, etc. Shipboard orientation data were available for Cores $4 \mathrm{H}$ through $6 \mathrm{H}$ and $12 \mathrm{H}$ through $16 \mathrm{H}$. Declination origins for the remaining cores have been adjusted so that the interquartile mean declination per section is zero,

Table 2. Magnetic properties of selected samples.

\begin{tabular}{|c|c|c|c|c|c|c|c|}
\hline Hole Specimen & $\begin{array}{l}\text { Depth } \\
\text { (mbsf) }\end{array}$ & Zone & $\begin{array}{l}H_{c r} \\
(\mathrm{Oe})\end{array}$ & $\begin{array}{c}K \\
\left(\mu \mathrm{G} / \mathrm{Oe}^{-1}\right)\end{array}$ & $\begin{array}{l}\text { NRM } \\
(\mu G)\end{array}$ & $\begin{array}{c}d l / d H \\
\left(\mathrm{MOe}^{-1}\right)\end{array}$ & $\begin{array}{c}\mathrm{Q} \\
(\mathrm{Oe})\end{array}$ \\
\hline 820 A 01-1-058 & 0.57 & $\mathrm{~S}$ & 456 & 6.9 & 8.23 & - & 1.19 \\
\hline $820 \mathrm{~A} 01-1-138$ & 1.37 & $\mathrm{~S}$ & 364 & 5.9 & 4.79 & 4.0 & 0.81 \\
\hline $820 \mathrm{~A} 01-2-078$ & 2.27 & A1 & 415 & 4.1 & 0.76 & - & 0.18 \\
\hline $820 \mathrm{~A} 01-3-038$ & 3.37 & A1 & 380 & 5.4 & 3.45 & 10.0 & 0.63 \\
\hline $820 \mathrm{~A} 01-4-078$ & 5.27 & B1 & 440 & 14.7 & 21.99 & - & 1.49 \\
\hline $820 \mathrm{~A} 01-4-138$ & 5.87 & B1 & & 15.0 & 20.25 & 2.4 & 1.35 \\
\hline $820 \mathrm{~B}$ 01-4-012 & 4.61 & B1 & 363 & 10.8 & 19.98 & - & 1.85 \\
\hline 820B 01-4-092 & 5.41 & B1 & 370 & 14.3 & 26.86 & - & 1.88 \\
\hline $820 \mathrm{~B}$ 01-5-132 & 7.31 & $\mathrm{Cl}$ & 245 & 25.4 & 5.99 & 2.0 & 0.23 \\
\hline $820 \mathrm{~A} 02-4-017$ & 11.86 & $\mathrm{~A} 2$ & 410 & 6.5 & 0.69 & - & 0.11 \\
\hline $820 \mathrm{~A}$ 03-3-035 & 20.04 & A2 & 341 & 3.0 & 0.25 & - & 0.08 \\
\hline 820 A 03-3-095 & 20.64 & $\mathrm{~A} 2$ & 367 & 4.0 & 0.27 & 5.0 & 0.07 \\
\hline $820 \mathrm{~A} \mathrm{03-7-017}$ & 25.86 & A2 & 375 & 3.4 & 0.06 & 7.0 & 0.02 \\
\hline $820 \mathrm{~A}$ 04-3-138 & 30.57 & B2 & 395 & 16.0 & 8.43 & 6.0 & 0.53 \\
\hline $820 \mathrm{~A} 04-4-037$ & 31.06 & $\mathrm{~B} 2$ & 440 & 18.5 & 15.39 & - & 0.83 \\
\hline $820 \mathrm{~A} 04-5-077$ & 32.96 & $\mathrm{C} 2$ & 270 & 34.5 & 15.09 & - & 0.44 \\
\hline 820 A $05-7-059$ & 45.28 & A & 328 & 4.4 & 0.54 & - & 0.12 \\
\hline 820 A $07-6-138$ & 63.57 & D & 454 & 14.6 & 10.79 & - & 0.74 \\
\hline 820 A $09-1-138$ & 75.07 & A & 343 & 3.5 & 0.47 & - & 0.13 \\
\hline $820 \mathrm{~A} 10-2-017$ & 84.86 & A & 363 & 0.9 & 0.23 & - & 0.25 \\
\hline $820 \mathrm{~A} 13-6-097$ & 120.16 & A & 334 & 3.5 & 0.44 & $\therefore$ & 0.12 \\
\hline 820 B $18-5-147$ & 167.66 & A & 390 & 3.9 & 0.32 & 16.0 & 0.08 \\
\hline 820 B $20-4-028$ & 179.57 & A & 432 & 3.6 & 0.45 & 14.0 & 0.12 \\
\hline 820 B 21-6-147 & 193.06 & A & 472 & 8.8 & 0.39 & 25.0 & 0.04 \\
\hline 820 B $28-1-147$ & 252.56 & A & 378 & 5.0 & 0.59 & 11.0 & 0.12 \\
\hline 820 B $38-2-107$ & 350.46 & A & 543 & 11.1 & 0.67 & 47.0 & 0.06 \\
\hline 820 B $40-2-067$ & 364.86 & A & 356 & 6.2 & 0.69 & 9.0 & 0.11 \\
\hline
\end{tabular}

Note: $K=$ volume susceptibility of wet sediment; $H_{e r}=$ coercivity of remanence; $d l / d H=$ slope of the normalized IRM vs, field curve at high field; $Q=N R M / K$.

and at high $(4.7 \mathrm{kHz})$ frequencies. A frequency-dependence coefficient, $K_{f d}$, expressed as a percentage, can be defined by

$$
K_{f d}=100 \times\left(K_{l f}-K_{h f}\right) / K_{l f}
$$

where $K$ denotes susceptibility per unit volume, and $l f$ and $h f$ refer to low and high frequencies. A corresponding definition holds for mass (specific) susceptibilities. High values of $K_{f d}$ (e.g., $10 \%$ or greater) are considered to reflect the presence of ultra-fine grains near the SD-SP size threshold (Thompson and Oldfield, 1986, p. 56). This threshold occurs at about $0.03 \mu \mathrm{m}$ for isometric magnetite grains (Dunlop, 1973).

Results for Holes $820 \mathrm{~A}$ and $820 \mathrm{~B}$ (combined using the susceptibility correlation discussed above) are plotted in Figure 12A. For weakly magnetic material, such as that encountered at Site 820 , the noise threshold for the determination of $K_{f d}$ is typically a few percent, but can be $5 \%$ or more for very low susceptibility samples. The errors inherent in measuring very low values of both $K_{l f}$ and $K_{h f}$ mean that
$K_{f d}$ is ill-determined and can show erratic variations with large spurious values. In such cases, Maher (pers. comm., 1991) suggested that just the difference $\left(K_{l f}-K_{h f}\right)$ provides a more stable measure of the presence of SP grains in very low susceptibility sediments. This difference is plotted in Figure 12B.

It is not clear which method for expressing results is preferable, as both have their limitations. Regardless of this, the important features are that high $K_{f d}$ and high $\left(K_{l f}-K_{h f}\right)$ values occur in the sharp susceptibility peaks (Zones $\mathrm{C} 1$ and $\mathrm{C} 2$ ), but not in the surface zones (Zones B1 and B2), or in Peak 3. This indicates that type-C sediments are characterized by a high SP content. The frequency-dependence test for SP grains does not work well in the background zone because of the large errors involved when measuring. However, values of $K_{f d}$ near $5 \%$ often occur; thus, some SP contribution may be present. Jackson (pers. comm., 1992) pointed out that both $K_{f d}$ and $\left(K_{l f}-K_{h f}\right)$ may substantially underestimate the importance of SP particles if a significant portion of the susceptibility arises from (frequency-independent) paramagnetic material. This is most probably the case for continental slope sites, such as Site 820 , that receive a significant influx of terrigenous clay material.

\section{ANHYSTERETIC REMANENT MAGNETIZATION}

The anhysteretic remanent magnetization (ARM) records for Holes $820 \mathrm{~A}$ and $820 \mathrm{~B}$ ( $>140 \mathrm{mbsf}$ ) are illustrated in Figure 13. A well-defined ARM is seen high in the uppermost zone and the usual three prominent peaks. However, the peaks do not have the same morphology as the corresponding susceptibility peaks. The significance of this becomes apparent when ARM is plotted vs. susceptibility, as shown in Figure 14. Banerjee et al. (1981) and King et al. (1982) showed how the distribution of points in ARM-susceptibility space is diagnostic of magnetic grain size, concentration and mineralogical variations. The data in Figure 14 fall into three clearly defined groups, labeled $\mathrm{A}, \mathrm{B}$, and $\mathrm{C}$, with distinct $\mathrm{ARM} / K$ ratios (this was the initial basis for introducing the $\mathrm{A}, \mathrm{B}$, and $\mathrm{C}$ classifications). The groups have been identified on the susceptibility record in Figure 2.

Group A corresponds to the background zone, with a low ARM/K ratio. Low values of $\mathrm{ARM} / K$ can result from a dominance of $\mathrm{MD}$ grains (Banerjee et al., 1981) or from grains near the SP/SD threshold that will have a high susceptibility but will not contribute much to the remanence. M. Jackson (pers. comm., 1992) pointed out that even the "low" ARM/K ratios in Group A are higher than expected for a pure MD assemblage. Points in Group A typically have ARM susceptibility $/ K$ ratios of 2 to 3 . These are near the SD-pseudo SD threshold values for magnetite (see Fig. 1 of King et al., 1982), whereas large MD grains give ratios of about 0.3 . According to Pierre Rochette (pers. comm., through Jackson, 1992), pyrrhotite has ARM/K ratios 

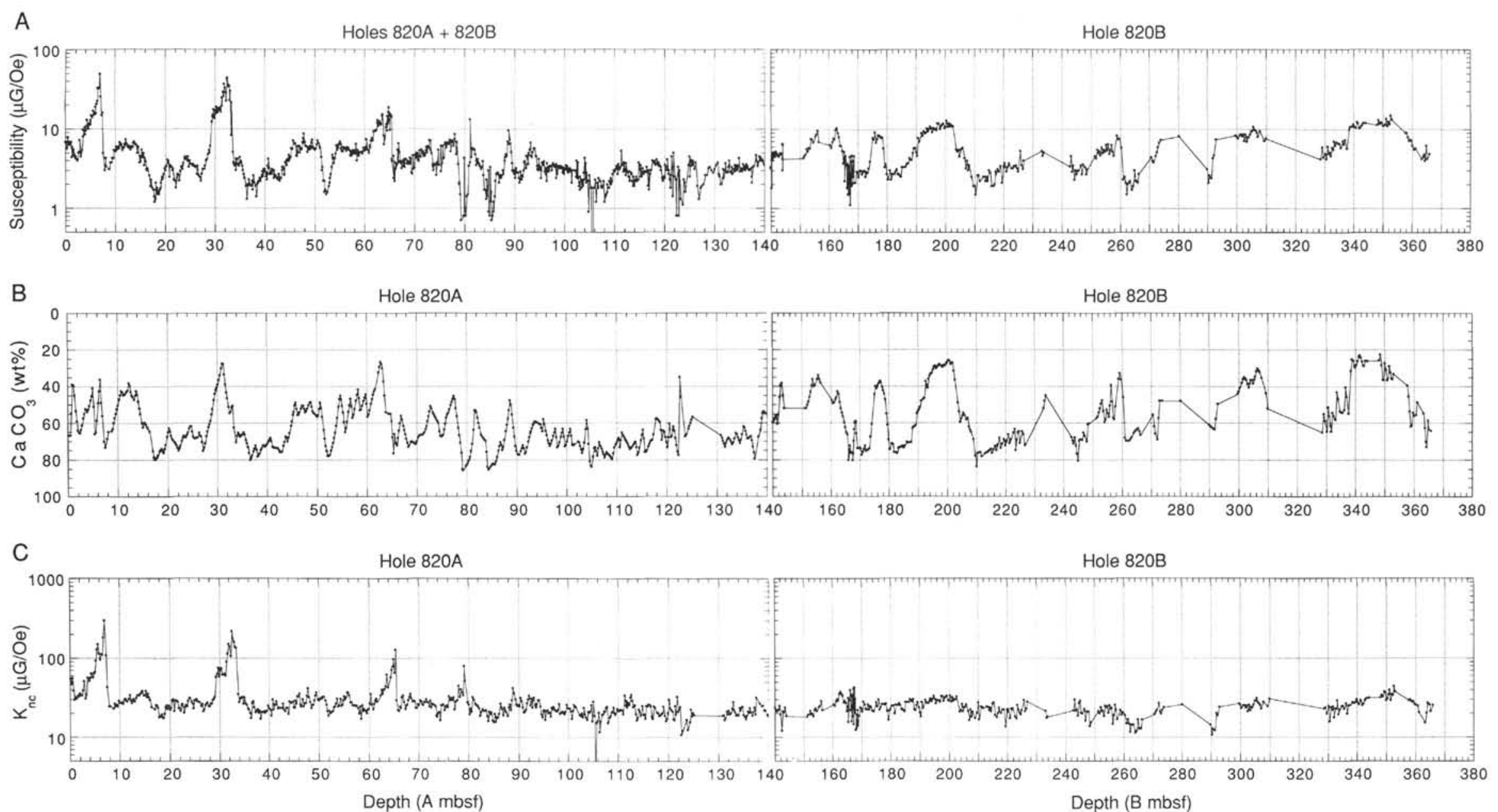

Figure 9. Comparison of (A) volume susceptibility of wet sediment; $(\mathbf{B})$ wt $\% \mathrm{CaCO}_{3} ;(\mathbf{C})$ volume susceptibility of the "dry noncarbonate" fraction, $K_{n c}$ (i.e., with the effects of carbonate dilution and seawater removed). The left part of (A) shows the combined data for Holes $820 \mathrm{~A}$ and $820 \mathrm{~B}$, plotted using the Hole $820 \mathrm{~A}$ depth scale. Note the change of depth scale at $140 \mathrm{mbsf}$. 


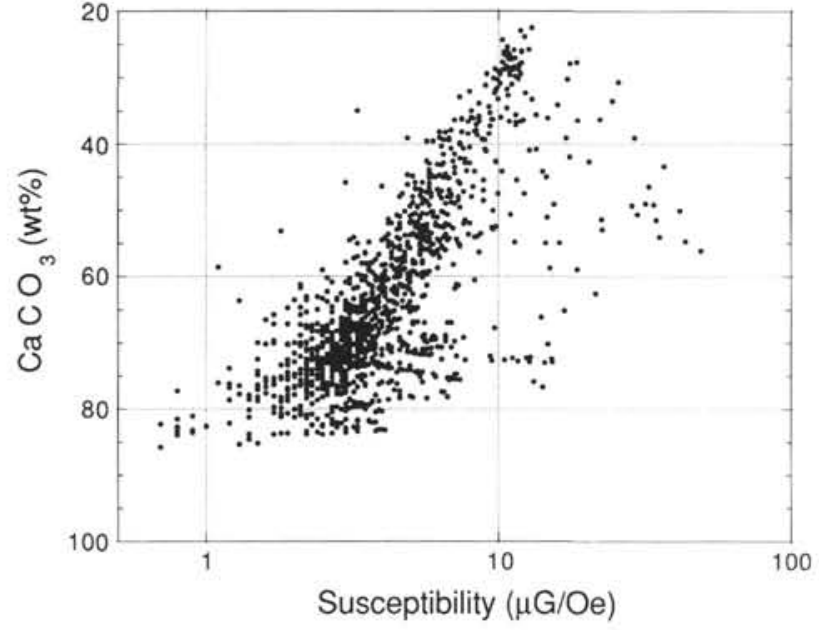

Figure 10. Plot of susceptibility vs. total calcium carbonate content for the combined Hole $820 \mathrm{~A}$ and $820 \mathrm{~B}$ records. A strong inverse correlation exists between wt $\% \mathrm{CaCO}_{3}$ and $\log$-susceptibility throughout most of the sequence, except in the sharp maxima of the main susceptibility peaks.

comparable to those found here. However, pyrrhotite is not identified in the core descriptions of the Shipboard Scientific Party, and its importance in these sediments must await further rock magnetic investigations. The fact remains that Zone A sediments carry a substantial VRM and no identifiable primary remanence. Thus, a MD assemblage, with some SP contribution, remains the simplest explanation at this stage.
The points in Group A are distributed along a straight line through the origin (Fig. 14 inset), indicating that the susceptibility variations in the background zone are controlled primarily by concentration, rather than by composition. This conclusion is supported by the $\mathrm{CaCO}_{3}$ results (discussed above), which indicate that carbonate dilution is responsible for much (though not all) of the susceptibility variations in Zone $\mathrm{A}$.

Group $\mathrm{B}$, with the highest $\mathrm{ARM} / K$ ratio, corresponds to the recovery phases (Zones B1 and B2). This is consistent with a high stability remanence carried by SD magnetite.

Group $\mathrm{C}$, corresponding to the sharp susceptibility maxima (Zone C), has intermediate $\mathrm{ARM} / K$ ratios. This probably results from a combination of stable SD grains (as per Group B) with a substantial, less stable, additional component. Both SP and MD magnetite have a higher susceptibility than SD grains (Thompson and Oldfield, 1986, p. 29). This is particularly so for SP grains. Thus, the addition of a large SP contribution in Zone $\mathrm{C}$ looks probable, as supported by the $K_{f d}$ data. The IRM acquisition curve for a sample from C1 (see below) indicates that the remanence is carried by almost pure magnetite. This disagrees with the introduction of a different, nonmagnetite-type mineral as an explanation for the behavior of Zone $\mathrm{C}$ properties.

Zone $\mathrm{S}$ is essentially type-B, consistent with the good magnetic stability of this surface layer. A single sample at the base of the surface zone is of type-C. Peak 3 is somewhat different from Peaks 1 and 2 and is predominantly of type-C, but sandwiches a central layer of type-B.

\section{ISOTHERMAL REMANENT MAGNETIZATION}

Variations of near-saturation IRM at $5000 \mathrm{Oe}$ (denoted as SIRM for convenience) are illustrated in Figure 15A for Hole 820B. This

\section{Hole $820 \mathrm{~A}$}

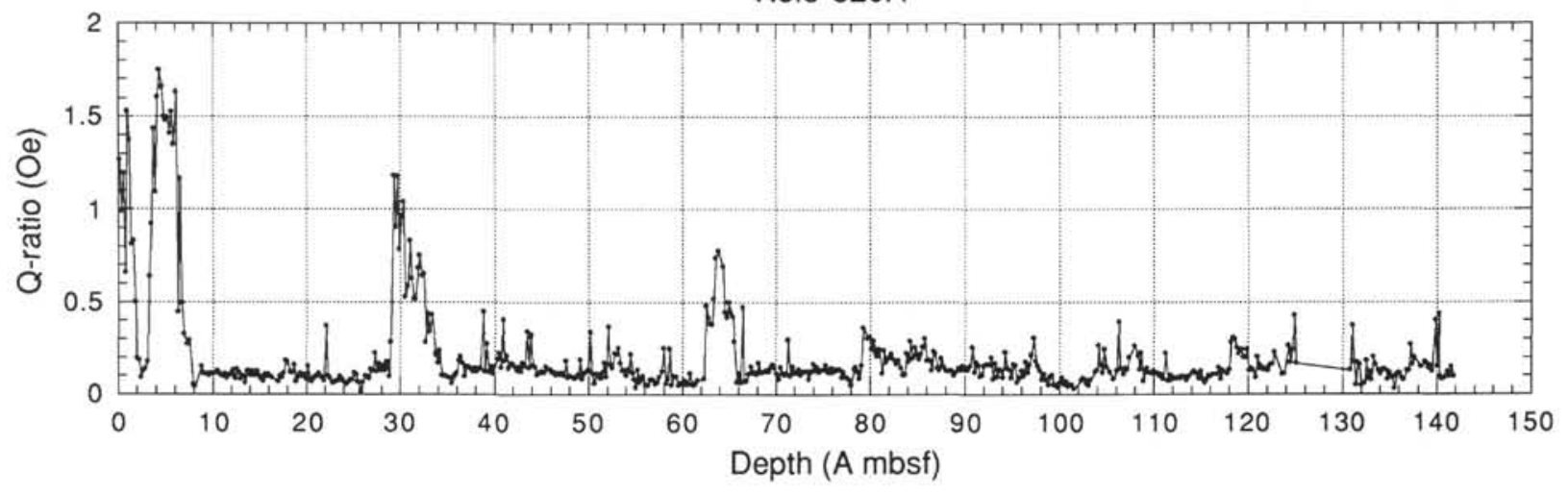

Hole $820 \mathrm{~B}$

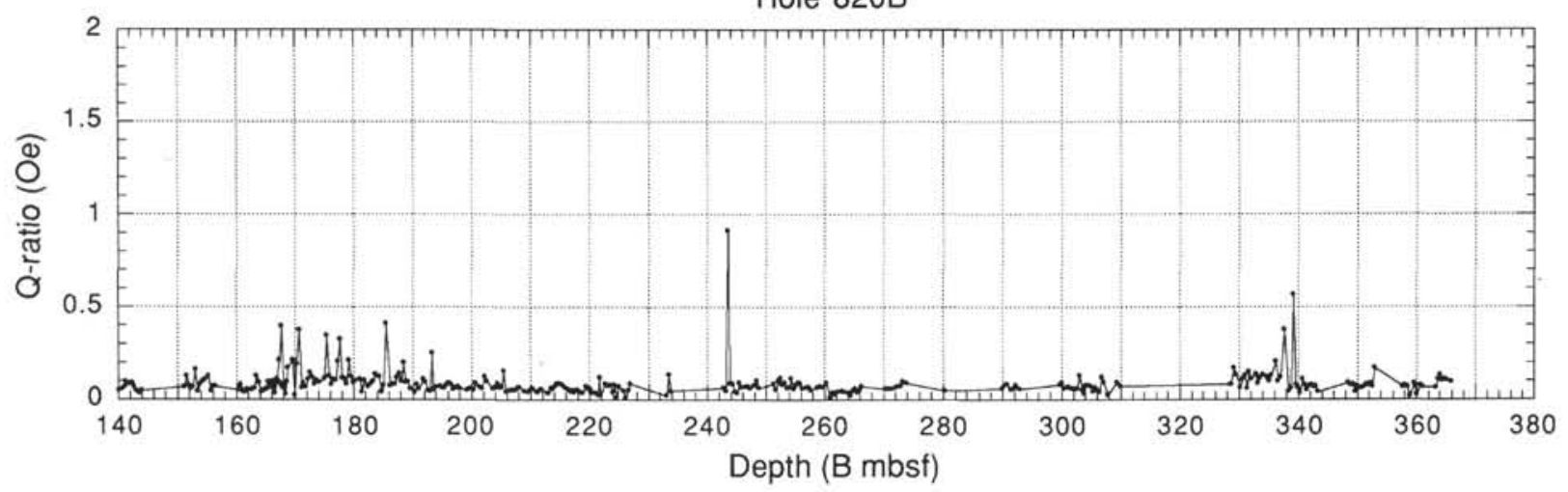

Figure 11. Q-ratios (=NRM/K) for Holes $820 \mathrm{~A}$ and $820 \mathrm{~B}$ below $140 \mathrm{mbsf}$. Several susceptibility values in Hole $820 \mathrm{~B}$ were near zero, producing Q-ratios that were spuriously high and plot off the scale (omitted from the plot). 
A
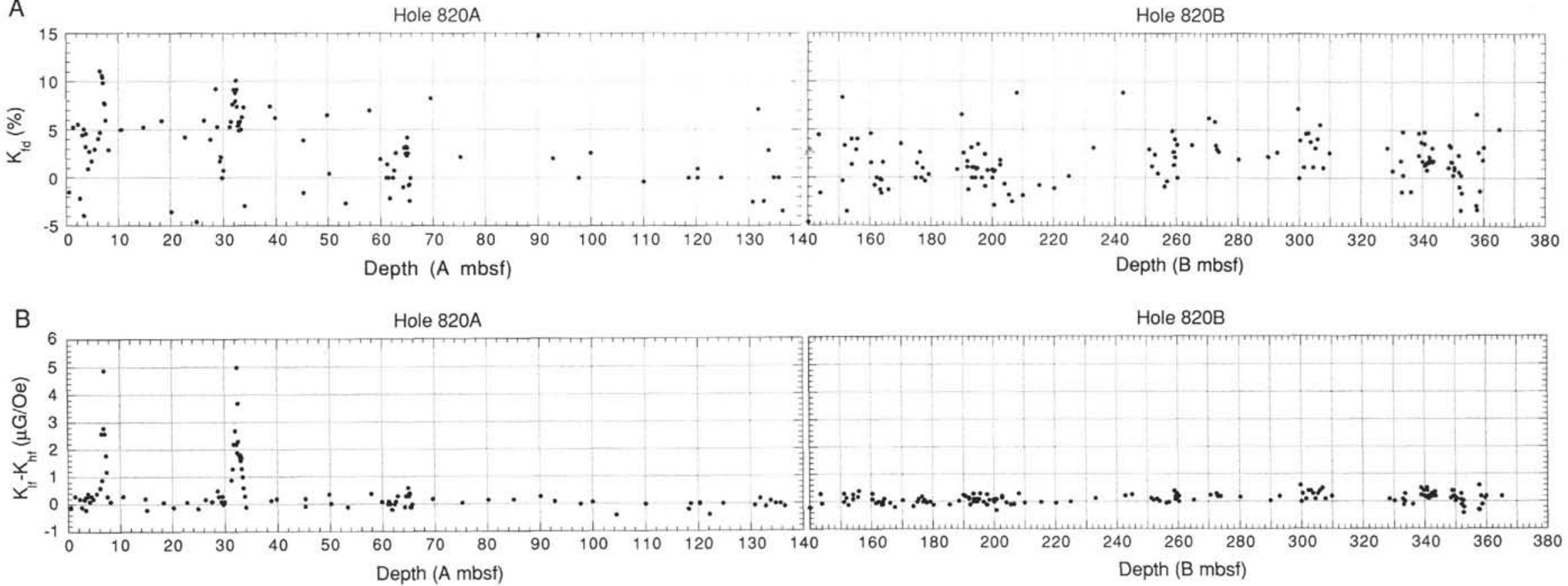

Figure 12. A. Coefficient of frequency-dependence of susceptibility, $K_{f d}$. B. Frequency difference of susceptibility, $K_{l f}-K_{h f}$ (as defined in the text). Above $140 \mathrm{mbsf}$, results from Holes $820 \mathrm{~A}$ and $820 \mathrm{~B}$ have been combined and were plotted using the Hole 820A depth scale. 
A
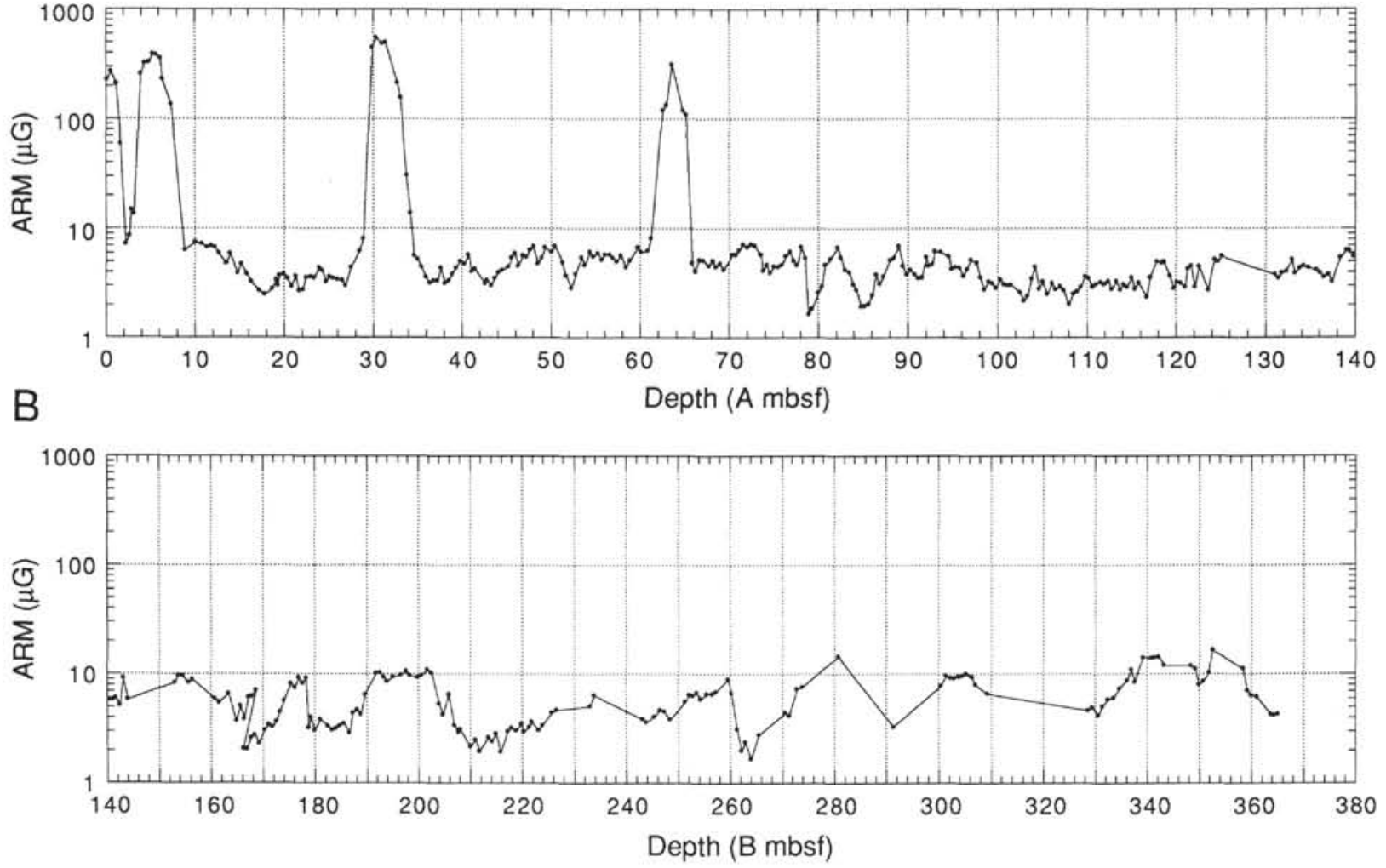

Figure 13. Plot of ARM vs. depth for (A) Hole 820A and (B) Hole 820B below $140 \mathrm{mbsf}$. ARM is imparted in an alternating field of $1000 \mathrm{Oe}$ with a DC bias of 0.4 Oe.

shows the familiar pattern of a high surface remanence and three main peaks superimposed on a low amplitude background. However, several distinct oscillations are apparent lower in the sequence. The distribution of points in an ARM/SIRM plot (not shown here) matches closely the $\mathrm{A}, \mathrm{B}$, and $\mathrm{C}$ grouping in the $\mathrm{ARM} / K$ diagram.

The common high-coercivity minerals (hematite and goethite) have saturation magnetizations that are typically 200 times lower than that for magnetite. Thus, the presence of a high-coercivity remanence, albeit a small one, can be important. Furthermore, the high-coercivity minerals have higher oxidation states than magnetite and thus can represent a different sedimentary regime. To provide a quick and simple test for the presence of high-coercivity material, the initial SIRM measurements at 5000 Oe $\left(S_{5}\right)$ were repeated later using a reverse field of $3000 \mathrm{Oe}\left(S_{-3}\right)$. The degree of undersaturation between 3000 and 5000 Oe was then expressed as a dimensionless percentage "coefficient of undersaturation":

$$
\text { CUS }=100 \times \frac{\left(S_{5}-S_{3}\right)}{S_{5}}
$$

High CUS values represent a large concentration of high-coercivity material and vice-versa. The linear gradient of the IRM acquisition curve between 3000 and $5000 \mathrm{Oe}(\mathrm{dI} / \mathrm{dH})$ is related to CUS by

$$
\frac{d I}{d H}=\frac{\text { CUS }=S_{5}}{400}
$$

For pure magnetite, CUS $=0$, and for hematite, CUS will be slightly above 80 .

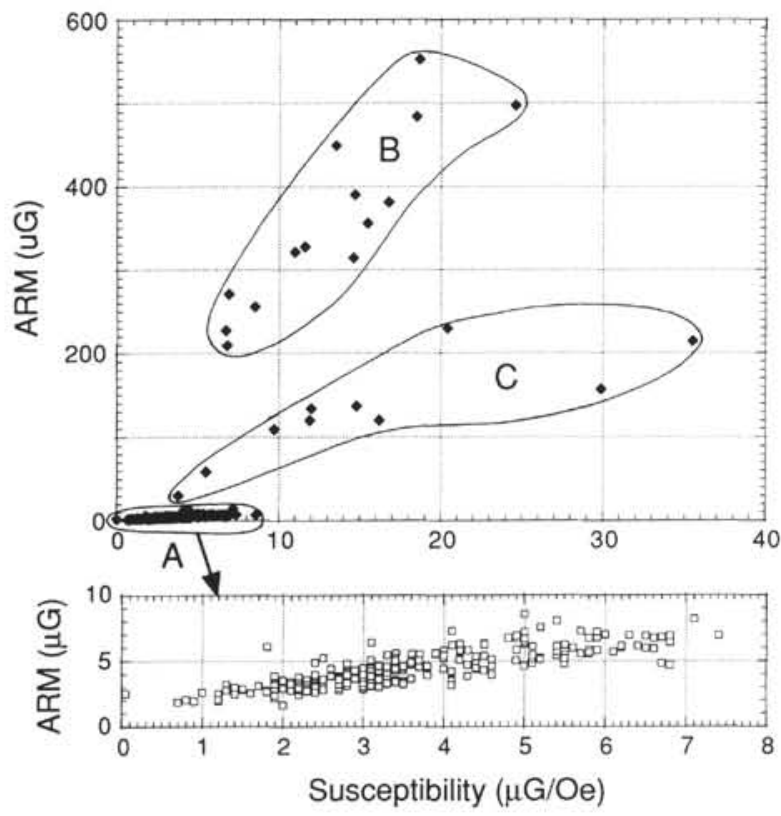

Figure 14. Plot of ARM vs, susceptibility. The data fall into three well-defined groups: $\mathrm{A}=$ low stability background (shown enlarged); $\mathrm{B}=$ high stability; $\mathrm{C}$ $=$ intermediate stability. 
A

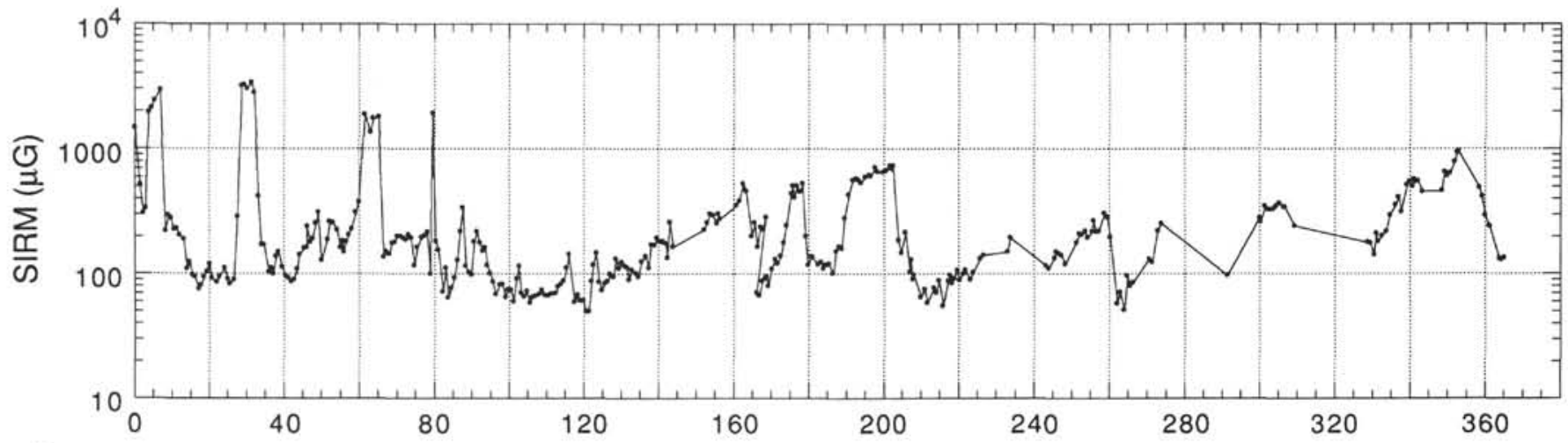

B

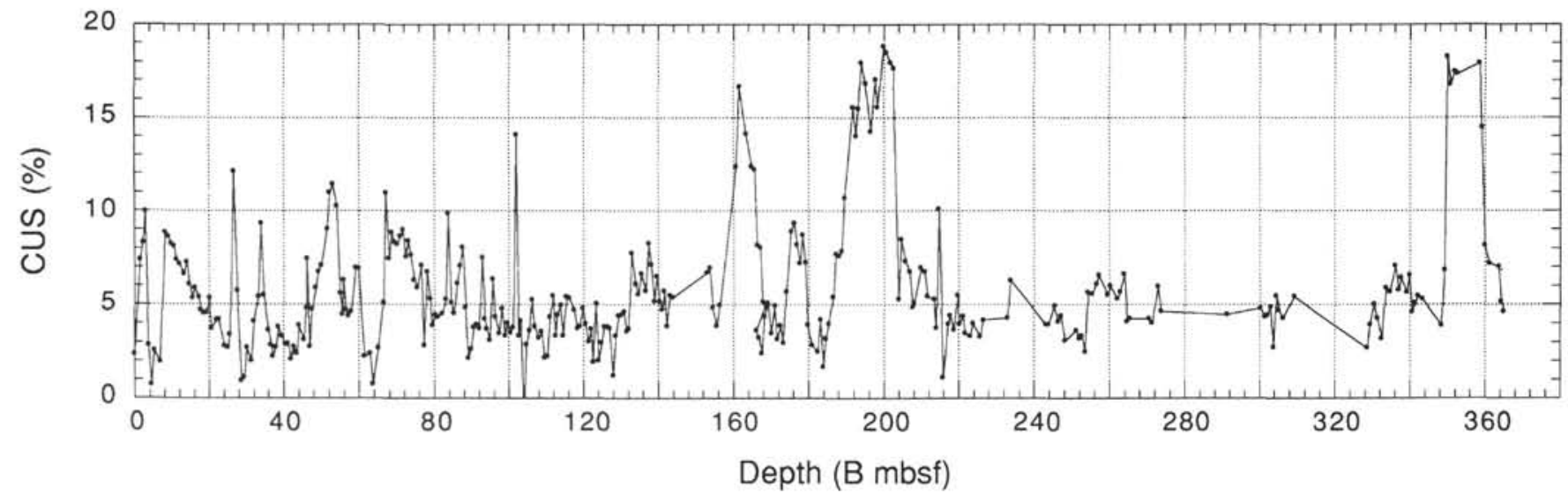

Figure 15. A. SIRM in a field of 5000 Oe. B. Coefficient of Undersaturation (CUS) for Hole 820B. CUS, as defined in the text, measures the degree of undersaturation of IRM between 3 and $5 \mathrm{kOe}$, expressed as a percentage of IRM at $5 \mathrm{kOe}$. It reflects the ratio of high:low coercivity material present.

CUS can be used as a measure of the volume ratio of hematite to magnetite. Assume that magnetite saturates below 3000 Oe and hematite saturates at $30000 \mathrm{Oe}$. If the ratio of saturation magnetization of magnetite to hematite is 200 (a theoretical upper limit), then for $10 \%$ magnetite, we find that CUS $=0.6$, and for $1 \%$ magnetite, $\mathrm{CUS}=6 . \mathrm{A}$ more practical value of the ratio of saturation magnetizations is probably nearer 50 , hence, CUS $=3$ for $10 \%$ magnetite $+90 \%$ hematite, and CUS $=20$ for $1 \%$ magnetite $+99 \%$ hematite. These figures are only approximate, but do show that low values of CUS are an indicator of a large hematite-to-magnetite volume ratio for the grains that carry magnetic remanence. Note that IRM curves for pyrrhotite (Dekkers, 1988) and maghemite will resemble that of magnetite, so this coercivity test will not distinguish between these minerals.

Figure 15B shows the variations of CUS for Hole $820 \mathrm{~B}$ and shows several interesting features. The surface zone and Peaks 1,2 , and 3 each show low CUS values, close to that of magnetite. The CUS decline from 9 down to $25 \mathrm{mbsf}$ might be a consequence of dissolution in a reducing environment. Background CUSs are typically about 5 , suggesting that volumetrically significant amounts of high-coercivity material are present throughout most of the sequence. Below 140 mbsf, three high-CUS zones stand out and are centered at about 162 , 195 , and 355 mbsf. These high coercivity features are found to relate to the sequence of upward-coarsening cycles identified by the sedimentologists (Feary, this volume). These features coincide with the fine-grained (mud) zone at the base of each cycle. The same relationship also holds for the other, smaller high-coercivity features (e.g., around 177 and $260 \mathrm{mbsf}$ ). We concluded that a large increase must be in the influx of hematite-type material during these intervals, and that redox conditions are such that these high-oxidation-state fine grains are able to survive.
Measurements of IRM as a function of applied field (up to 5000 Oe), performed on 14 specimens, are entirely consistent with the CUS data discussed above. In general, types $\mathrm{B}$ and $\mathrm{C}$ samples show a magnetite-type response and reach saturation by about $2000 \mathrm{Oe}$ (Fig. 16). The surface zone is similar, saturating at fields slightly greater than 3000 Oe. Results for a high-coercivity zone are illustrated for a

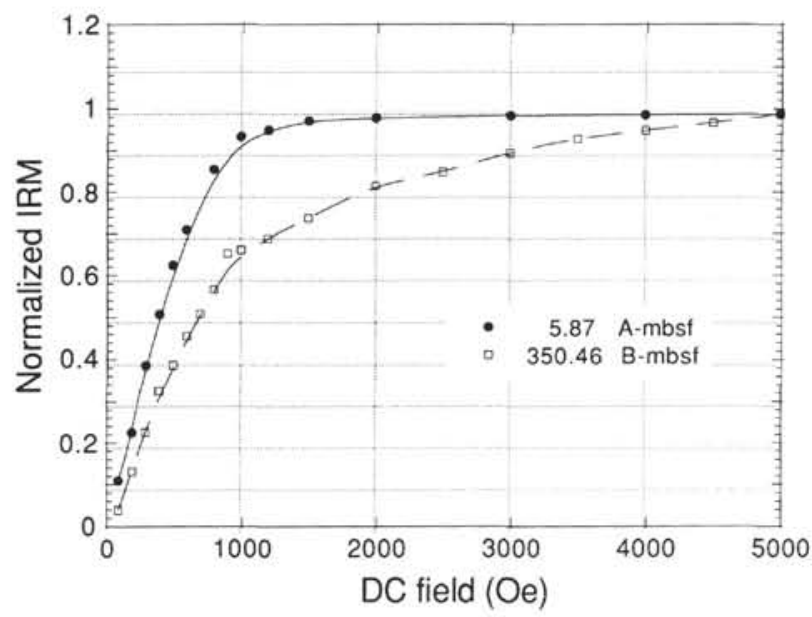

Figure 16. IRM acquisition curves for samples from Holes $820 \mathrm{~A}, 5.87 \mathrm{mbsf}$ (Zone B1) and $820 \mathrm{~B}, 350.46 \mathrm{mbsf}$. The sample at $5.87 \mathrm{mbsf}$ is characteristic of type-B and - $\mathrm{C}$ sediments; the sample at $350.46 \mathrm{mbsf}$ comes from one of the prominent "high-CUS" zones that are rich in high-coercivity material. 
specimen from Hole $820 B, 350.46$ mbsf. Some values of the gradient $(d I / d H)$ of the normalized IRM vs. field plot approaching $5000 \mathrm{Oe}$ are included in Table 2 to illustrate the behavior of the main sediment types. The gradient is related to CUS by Equation 2 .

\section{LOWRIE-FULLER TEST}

Lowrie-Fuller tests (Lowrie and Fuller, 1971; Dunlop, 1983) were performed on 15 specimens to help elucidate the domain state of the principle magnetic zonations. Specimens from Zones B and C and from the surface zone, gave positive test results (i.e., ARM more resistant to AF demagnetization than SIRM) (Fig. 17A). In several specimens from Zones $\mathrm{B}$ and $\mathrm{C}$, the $\mathrm{AF}$ demagnetization plots for $A R M$ and SIRM crossed from harder ARM to harder SIRM between 300 and 500 Oe (Fig. 17B). Background (A) specimens gave either a negative result (Fig. 17C), or, more commonly, showed similar coercivity for ARM and SIRM out to about 300 Oe and a harder SIRM thereafter (Fig. 17D). Particle interactions and varying admixtures of SP grains are probably complicating some of the test results. Bearing this in mind, the simplest interpretation is that Zones B and C and the surface zone are dominated by stable SD carriers, whereas background Zone A contains MD carriers, possibly with some SP grains.

\section{COERCIVITY OF REMANENCE}

Coercivities of remanence $\left(H_{c r}\right)$ were determined in 26 specimens by first applying a DC field of $5000 \mathrm{Oe}$, then determining the reverse DC field that reduces the remanence to zero. The results are summarized in Table 2 and plotted in Figure 18 as a function of susceptibility. Most specimens have $H_{c r}$ values that range between 310 and $470 \mathrm{Oe}$, with one high value ( $543 \mathrm{Oe}$ ) at $350.46 \mathrm{mbsf}$ in Hole $820 \mathrm{~B}$. Peak Zones $\mathrm{C} 1$ and $\mathrm{C} 2$ are distinct and have a low $H_{c r}(270 \mathrm{Oe})$ and high susceptibility. The specimen from Peak 3 falls within the cluster for Zone B.

McElhinny (1973, p. 104) quoted 400 Oe as the bottom of the range of $H_{c r}$ for stable NRM in magnetite, and Thompson and Oldfield (1986, p.23) gave $H_{c r}=300$ Oe for SD magnetite, 150 Oe for MD magnetite, and 7000 Oe for hematite. Assemblages of SP magnetite grains have low values of $H_{c r}$. Most of the sediments from Site 820 thus have $H_{c r}$ values in the SD magnetite range.

The high $H_{c r}$ values occur for background samples that have a relatively high $d I / d H$ slope (i.e., high-coercivity fraction: see Table 2 , Hole $820 \mathrm{~B}, 350.46 \mathrm{mbsf}$, for an example). We are probably seeing the effect of a small amount of high-coercivity material producing a large increase in $H_{c r}$ (Kneller and Luborsky, 1963). $H_{c r}$ values for
A

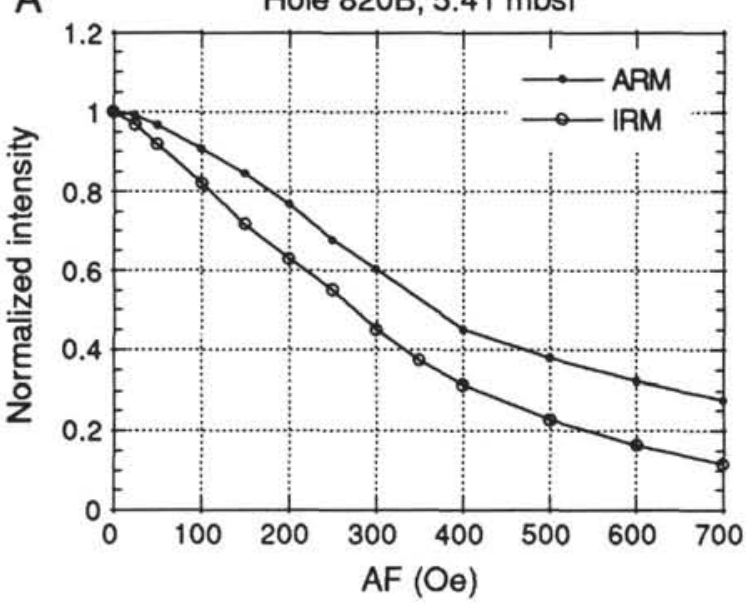

C

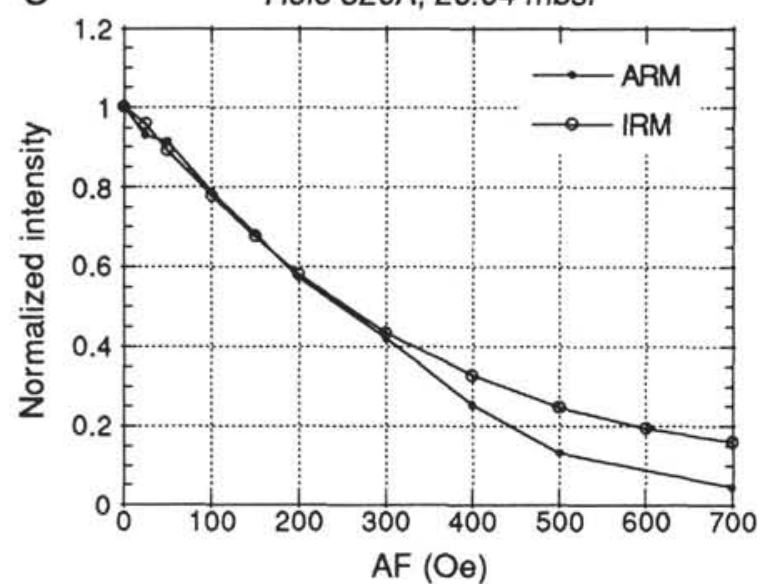

B

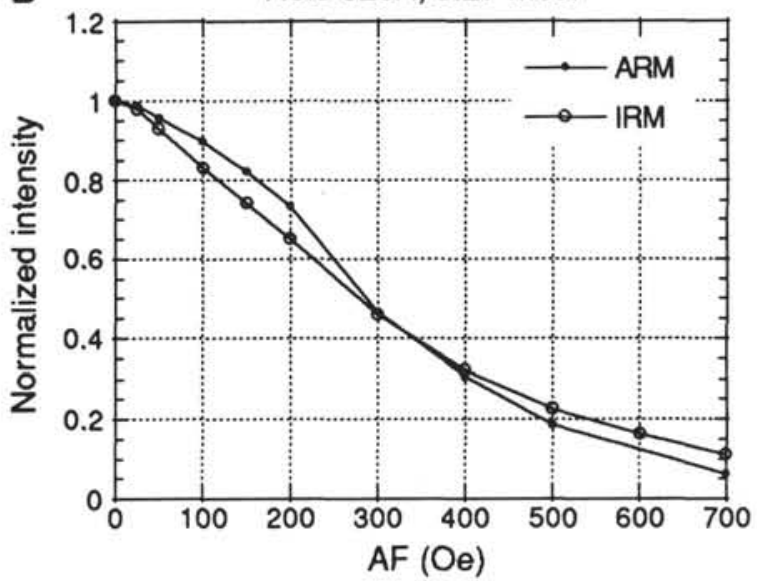

D

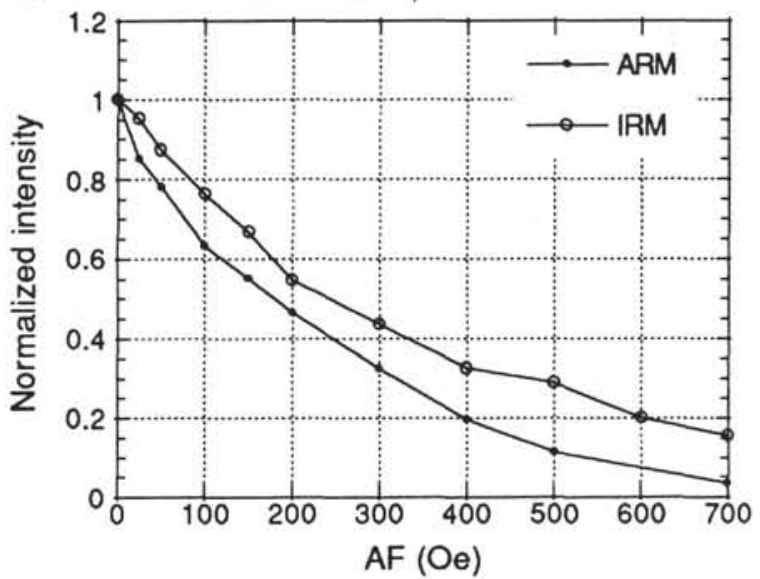

Figure 17. Typical Lowrie-Fuller test results. A. Hole 820B, $5.41 \mathrm{mbsf}-$ typical of Zones B and C. B. Hole 820A, 5.27 mbsf-typical of Zones B and C, with crossover. C. Hole 820A, $20.04 \mathrm{mbsf}$ - background Zone A, showing similar coercivity spectra. D. Hole 820A, 84.86 mbsf-typical of background Zone A. 


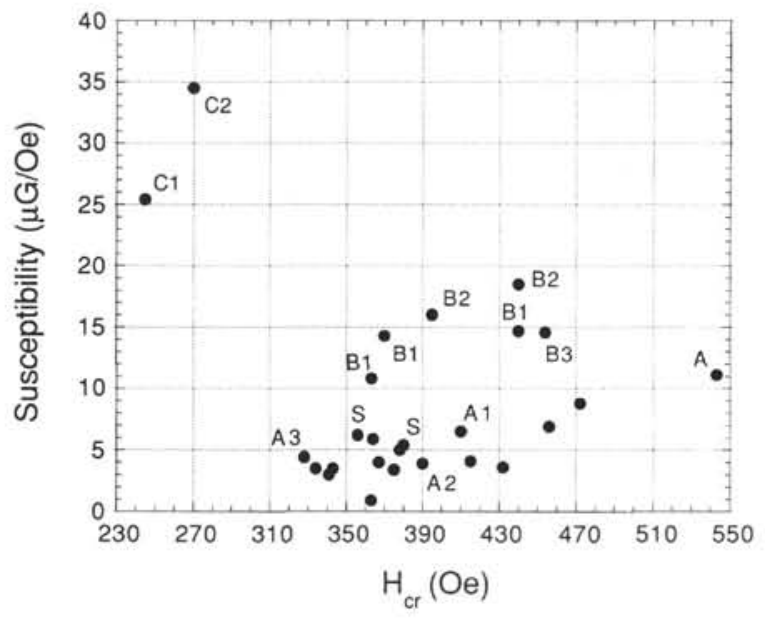

Figure 18. Plot of coercivity of remanence $\left(H_{c r}\right)$ vs, susceptibility. Sediment zones are designated as $\mathrm{S}=$ surface, $\mathrm{A}=$ background, $\mathrm{B}=$ recovery phase, and $\mathrm{C}=$ peak susceptibility.

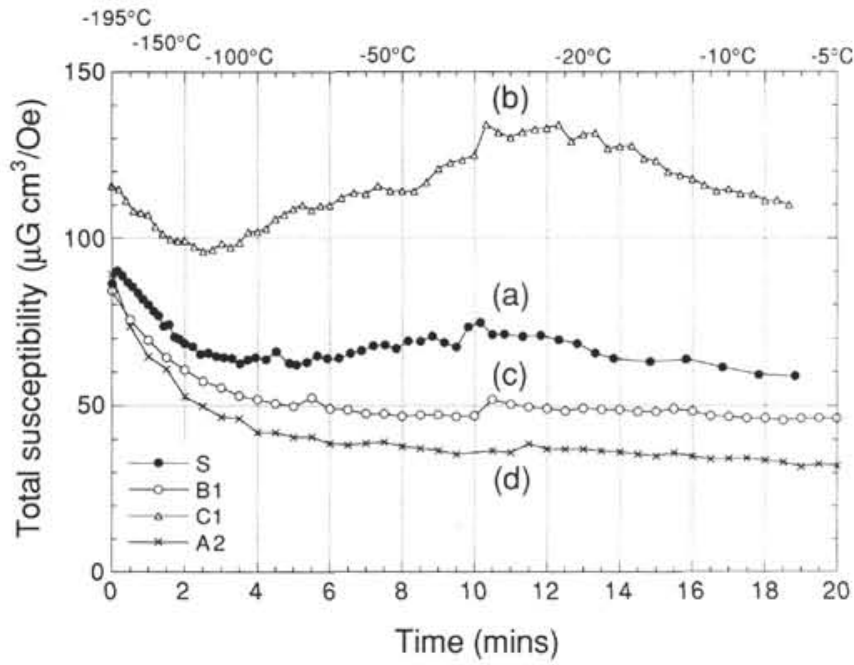

Figure 19. Low-temperature dependence of susceptibility of (A) the surface zone, (B) the B zones, (C) the C zones, and (D) the background A zones. Temperature vs, time relationships are $-150^{\circ} \mathrm{C}$ at $1.5 \mathrm{~min},-100^{\circ} \mathrm{C}$ at $3.5 \mathrm{~min}$, $-50^{\circ} \mathrm{C}$ at $7.5 \mathrm{~min},-10^{\circ} \mathrm{C}$ at $17 \mathrm{~min}, 0^{\circ} \mathrm{C}$ at $25 \mathrm{~min}$, and room temperature $\left(23.5^{\circ} \mathrm{C}\right)$ after 40 to $80 \mathrm{~min}$.

background Zone $\mathrm{A}$ are in the $\mathrm{SD}$, rather than the $\mathrm{MD}$, magnetite range, which suggests either that $\mathrm{MD}$ effects are swamped by a high-coercivity contribution, or that the source of the VRM, low-magnetic stability, and negative Lowrie-Fuller test results from the presence of some magnetic mineral phase other than MD magnetite. A significant contribution from magnetite grains near the SP-SD threshold is expected to give lower $H_{c r}$ values than those observed.

The B zone, which carries a relatively stable remanence, has $H_{c r}$ values near that of SD magnetite. Low values of $H_{c r}$ in Zones $\mathrm{Cl}$ and $\mathrm{C} 2$ (which also carry a relatively stable natural remanence and give a positive Lowrie-Fuller test) still lie above the MD magnetite range and attest to the presence of a SP contribution, or possibly a mixture of different magnetic mineral phases.

\section{LOW TEMPERATURE TESTS}

As a simple test of the low temperature dependence of susceptibility, 18 samples were immersed in liquid nitrogen $\left(-195^{\circ} \mathrm{C}\right)$ for 20 min, then measured repeatedly in a susceptibility bridge as they warmed to room temperature. The temperature $(T)$ in the middle of a static test specimen was $-150^{\circ} \mathrm{C}$ after $1.5 \mathrm{~min},-100^{\circ} \mathrm{C}$ after $3.5 \mathrm{~min}$, $-50^{\circ} \mathrm{C}$ after $7.5 \mathrm{~min},-10^{\circ} \mathrm{C}$ after $17 \mathrm{~min}, 0^{\circ} \mathrm{C}$ after $25 \mathrm{~min}$, and room temperature $\left(23.5^{\circ} \mathrm{C}\right)$ after 40 to $80 \mathrm{~min}$. The mean temperature of a specimen during measurement should be somewhat higher than these figures suggest. The basic types of responses expected are (1) a Curie-Weiss, $K=\mathrm{C} / \mathrm{T}$ decay for paramagnetic material, (2) an increase of susceptibility with temperature from grains near the SP-SD threshold becoming unblocked, (3) little change in susceptibility for SD grains, and (4) a peak in susceptibility at, or above, about $-150^{\circ} \mathrm{C}$ for MD magnetite. The MD magnetite peak will appear to shift to higher temperature, or be completely obscured, should a mixture of MD and SP grains occur. Sediments from the continental slope contain significant clay fractions, so a substantial part of the susceptibility signal will be of paramagnetic origin. This dominates the low-temperature results and tends to swamp any MD responses.

Each of the four main sediment types gives a characteristic behavior (Fig. 19).

1. Surface samples produce a generally flat response, suggesting a preponderance of SD carriers. A gentle increase from about $4\left(-85^{\circ} \mathrm{C}\right)$ to $10 \mathrm{~min}\left(-30^{\circ} \mathrm{C}\right)$, has been attributed to grains near the SP-SD threshold, superimposed on a weak paramagnetic decay. The small kink at $1.5 \mathrm{~min}\left(-150^{\circ} \mathrm{C}\right)$ may indicate a minor MD contribution.

2. Type-B samples give a flat (SD) response superimposed on a weak paramagnetic background. The SP effect is absent, and no suggestion of a MD peak is seen at or above $-150^{\circ} \mathrm{C}$.

3. Type-C samples exhibit a strong SP increase from about 3 $\left(-100^{\circ} \mathrm{C}\right)$ to $12 \mathrm{~min}\left(-25^{\circ} \mathrm{C}\right)$, superimposed on a relatively weak paramagnetic decay. Even approaching room temperature, the susceptibility stays well above the $-115^{\circ} \mathrm{C}(2.5 \mathrm{~min})$ minimum value.

4. Type-A (background) samples exhibit the most pronounced paramagnetic decay and an absence of SP effects. Sometimes, there is the suggestion (as in Fig. 19D) of a kink near $-150^{\circ} \mathrm{C}(1.5 \mathrm{~min})$, but otherwise, little evidence for an MD contribution can be seen. This is surprising and suggests that our preferred MD explanation for low stability, low $\mathrm{ARM} / K$ ratio, and VRM in the background zone may be too simplistic and that other minerals/phases may be present. The common iron sulfides are not expected to have any major effect on the susceptibility record - pyrite is paramagnetic, and phyrrhotite has a susceptibility that is about one-tenth that of magnetite or maghemite.

Three of the Zone A samples studied were taken from close beneath $\mathrm{C}$ zones (Hole 820A: 9.06, 10.56, and $34.66 \mathrm{mbsf}$ ). Each showed evidence for a modest SP contribution. Thus, the onset of the SP fraction responsible for the sharp susceptibility maxima may slightly pre-date the actual zone boundary in the susceptibility record.

One further test was applied to try to resolve the uncertainty about the dominant domain state of type-A sediments. Seven samples were given a strong IRM at liquid nitrogen temperature, then their remanence was measured repeatedly as they warmed to room temperature, while maintaining the samples in the zero field at all times. The expected response for an assemblage of grains near the SP-SD size threshold is a steady decrease in remanence as SD grains near the boundary become progressively unblocked with increasing temperature. The remanence of stable SD grains would be relatively unaffected. MD grains would show a significant loss of remanence at the Verwey and $T_{1}$ transitions near $-150^{\circ} \mathrm{C}$ (e.g., Hodych, 1991).

All samples tested showed a steady decrease of remanence as they warmed up. The results were found to be reproducible, with little within-zone scatter. The effect in the background zone was almost four times stronger than in Zones B and C, with the average percentage remanence remaining after warming being $13 \%$ for type-A samples (three), $48 \%$ for type-B samples (two), and $42 \%$ for type-C samples (two). Type-A sediments tended to have a clear, though small, kink in the remanence curves near $150^{\circ} \mathrm{C}$. 
The higher fractions of remanence remaining in the type- $\mathrm{B}$ and $-\mathrm{C}$ samples is consistent with the presence of stable SD grains. The behavior of the type-A samples is consistent with the presence of a mixture of MD and SP grains. In view of the $K_{f d}$ results, we were surprised that the type- $\mathrm{C}$ samples did not give the largest decay in remanence. We concluded that type-B samples have the lowest SP content (as expected), and that SP grains may be more prevalent in the background zone than was revealed by the previous tests.

\section{BIOGENIC MAGNETITE}

Chains of SD-sized crystals of pure magnetite are characteristic of biogenically produced (bacterial) magnetite (Blakemore and Frankel, 1981) and are being found increasingly in marine environments as the search for them proceeds (e.g., Yamazaki et al., 1991). Some caution is needed when interpreting the results, because (1) clustering into chains might be produced during the magnetic extraction process, (2) the sizes of the magnetic grains can be influenced by dissolution, and (3) dissolution will favor the formation of isometric particles that will resemble biogenic magnetite crystals (Maher, pers. comm., 1991).

Magnetic extracts from four samples from Hole 820A were examined using a TEM by Paul Hesse, from the Australian National University, Canberra. Evidence for chains of SD-sized magnetite crystals were present in each sample (Fig. 20). Relative abundances of such occurrences are summarized in Table 3. Hesse (pers. comm., 1991) also found that chains of magnetite crystals are common in Eltanin cores from various locations in the Tasman Sea and have a range of morphologies that are similar to those found in Hole 820A.

We concluded (on the basis of only four samples!) that biogenic magnetite is present and that it varies in abundance with the bulk magnetization of the sediments. We do not yet know how much of the magnetic signal was of biogenic origin, or whether the biogenic magnetite present was produced in situ or transported to Site 820 as detritus.

\section{DISCUSSION}

The properties outlined above combine to indicate that the remanence in the upper zone ( $<2 \mathrm{mbsf}$ ) is carried mainly by SD magnetite grains. Such a scenario is common in the upper part of marine carbonate-rich cores, where very fine-grained primary iron oxides are still preserved. The low, and decreasing, MDFs below about $2 \mathrm{~m}$ (except for the high-susceptibility zones) are consistent with the selective removal and/or alteration of SD $(0.03-1 \mu \mathrm{m})$ grains by sulfate reduction processes (Karlin and Levi, 1983). Because large grains have a greater volume-to-surface area ratio, we can expect that they will survive preferentially during dissolution. Thus, any assemblage of grains will tend to become more MD-like as dissolution proceeds, except in the final stage before extinction. The Shipboard Scientific Party (1991) has already drawn attention to the strong sulfate gradient downcore, and the presence of iron monosulfides was mentioned (briefly) in the core descriptions.

The simplest explanation for the three distinct groups (A, B, and $\mathrm{C}$ ) in the $\mathrm{ARM} / K$ diagram is in terms of differences that arise from magnetic grain-size variations. Type-B specimens have the highest $\mathrm{ARM} / K$ ratio, which is consistent with stable SD magnetization carried

Table 3. Summary of biomagnetic results.

\begin{tabular}{ccclcrr}
\hline $\begin{array}{c}\text { Core, section, } \\
\text { interval }(\mathrm{cm})\end{array}$ & $\begin{array}{c}\text { Depth } \\
(\mathrm{mbs})\end{array}$ & Zone & Concentration & Occurrence & $\begin{array}{r}\mathrm{NRM} \\
(\mu \mathrm{G})\end{array}$ & $\begin{array}{r}K \\
\left(\mu \mathrm{G} / \mathrm{Oe}^{-1}\right)\end{array}$ \\
\hline 133-820A- & & & & & & \\
$1 \mathrm{H}-1,78$ & 0.77 & $\mathrm{~S}$ & Low & 90 & 4.1 & 6.3 \\
$1 \mathrm{H}-4,58$ & 5.07 & B1 & Mod/high & 179 & 18.9 & 12.8 \\
$1 \mathrm{H}-5,18$ & 6.17 & B1/C1 & High & 343 & 25.3 & 15.5 \\
$2 \mathrm{H}-3,57$ & 10.76 & A2 & Low/trace & $4 ?$ & 0.6 & 5.7 \\
\hline
\end{tabular}

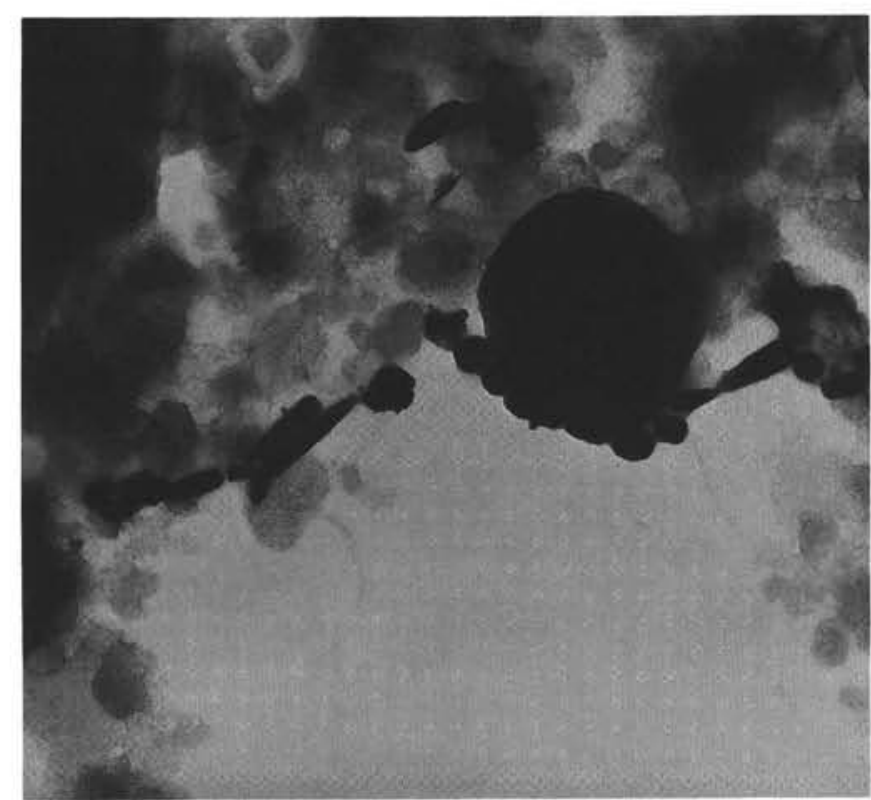

$0.5 \mu \mathrm{m}$

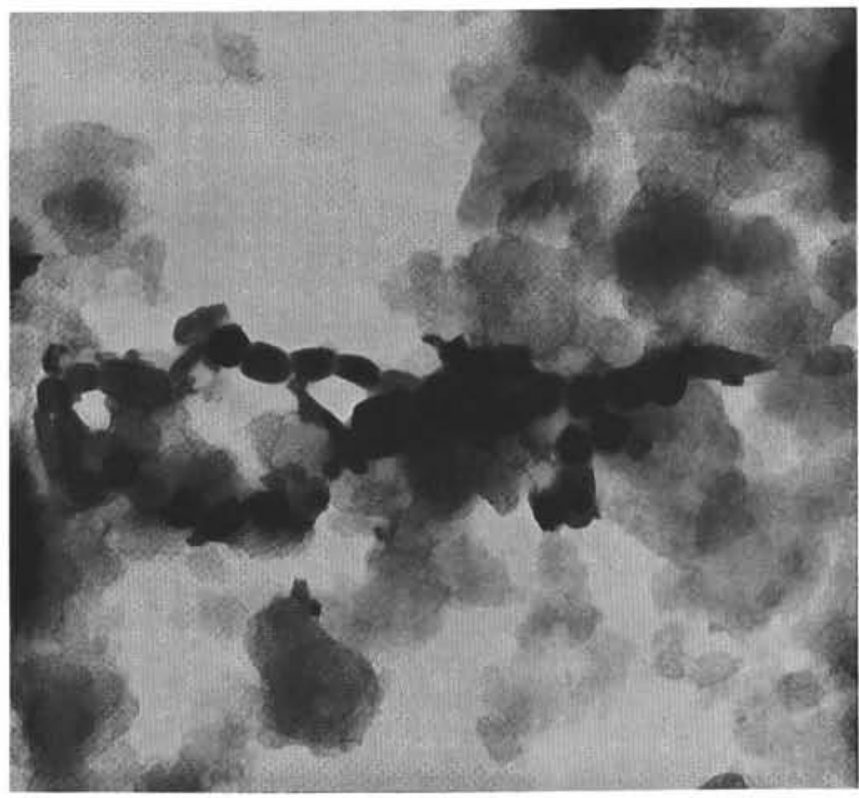

Figure 20. TEM photographs of magnetic extracts from Hole $820 \mathrm{~A}, 6.17 \mathrm{mbsf}$, showing chains of SD-sized opaque crystals characteristic of biogenically produced magnetite.

by magnetite. Intermediate ratios for Group $\mathrm{C}$ may have resulted from type- $\mathrm{B}$ background with an additional ultra-fine, superparamagnetic contribution (indicated by the associated high-frequency dependence of susceptibility). The domain state of the type-A sediments that comprise the bulk of the sequence (excluding the prominent peaks) remains enigmatic. A MD origin, with some $\mathrm{SP}$ contribution has been adopted at this stage, although this is not entirely satisfactory because of the magnitude of the ARM $/ K$ ratios. 
The linearity of the $\mathrm{ARM} / K$ plot for Group A shows that the dominant ferrimagnetic composition of the background is uniform and that the observed fluctuations in remanence and susceptibility result primarily from variations in magnetic mineral concentration (controlled largely by carbonate dilution).

The significance of the A, B, and C classifications of magnetic properties becomes apparent when relationships with the $\delta^{18} \mathrm{O} / \mathrm{sea}$ level record of Peerdeman et al. (this volume) are considered. From independent evidence of fluctuations in sea level for the Great Barrier Reef and from radiocarbon dating of the upper $10 \mathrm{~m}$ of Hole $820 \mathrm{~A}$, Peerdeman and Davies (this volume) have established that enriched (high) $\delta^{18} \mathrm{O}$ values occur during periods of low sea level, and viceversa. This is consistent with the global ice-volume interpretation of oxygen isotope records from around the world. Peerdeman and Davies define early and late stages for the marine transgressions following each principal lowstand in sea level and also note that the three prominent magnetic susceptibility peaks (at about 7, 32, and 64 mbsf) occur at, or just after, maxima in the $\delta^{18} \mathrm{O}$ record (i.e., during low sea-level conditions). Peak values of magnetic susceptibility persist during most of the early transgression, then return to relatively low values during the late transgressive period that followed each glacial maximum. The interglacials have been characterized by relatively low susceptibility (Zone A) .

Thus, the distinctive A, B, and C classifications of magnetic properties can be interpreted directly in terms of major glacio-sea-level variations and the transgression classification of Peerdeman and Davies. Lowstands in sea level during glacial maxima and early transgressive periods produce $\mathrm{C}$-type sediments; the subsequent late marine transgressions produce B-type sediments; and A-type sediments occur under relatively high sea-level conditions during the interglacials.

The magnetic susceptibility record for Hole $820 \mathrm{~A}$, plotted on a logarithmic scale, and the $\delta^{18} \mathrm{O}$ record are compared in Figure 21. Peerdeman et al. suggest that the trend in the $\delta^{18} \mathrm{O}$ record may be due to a regional temperature overprint that affected part of the record. This trend has been removed from the $\delta^{18} \mathrm{O}$ data plotted in Figure 21, in the expectation that the record will reflect more accurately the variations in sea level. One might find it worthwhile to make overlays for Figure 21 because the correlation between the two records is most revealing. Throughout the background (A zone) below $20 \mathrm{mbsf}$ a one-to-one negative correlation between susceptibility and $\delta^{18} \mathrm{O}$ occurs. This breaks down at the glacial maximum, and during low sea-level/early transgression conditions (type-C magnetic properties), when a switch to a positive correlation occurs between the two records. Note that in Peak 3 ( $\sim 64 \mathrm{mbsf}$ ), it looks more as though the negative $\delta^{18} \mathrm{O}$ step comes about $2 \mathrm{~m}$ after the positive susceptibility step. During the late marine transgressive phases (type-B magnetic properties), the negative correlation gradually was re-established.

Above $20 \mathrm{mbsf}$, the picture is less straightforward. Following the most recent glacial maximum (oxygen isotope Stage 2, at $7 \mathrm{mbsf}$ ) the positive correlation between susceptibility and $\delta^{18} \mathrm{O}$ persisted. In addition, the $\delta^{18} \mathrm{O}$ record between 8 and $20 \mathrm{mbsf}$ shows relatively little variation, with no counterparts for the susceptibility low at about $18 \mathrm{mbsf}$ or the broad high between 10 and $16 \mathrm{mbsf}$. (The latter may be explained if the positive correlation above $7 \mathrm{mbsf}$ is extended down to about 16 mbsf.)

Therefore, two distinct mechanisms must be responsible for the susceptibility signature of sediments at Site 820: one for the background zones, where there is a negative susceptibility- $\delta^{18} \mathrm{O}$ correlation and the sediments have type-A characteristics, and another for the main susceptibility peaks, where a positive (or no) correlation exists and the sediments have characteristics of both types C and B. In particular, we need to explain why an influx of ultra-fine (SP) material coincided with the lowstands in sea level and early transgressions at Peaks 1,2, and 3, and why the succeeding late transgressive periods produced stable SD (type-B) sediments.

A pertinent question is why susceptibility peaks (such as Peaks 1 , 2 , and 3 ) have not been found at other maxima in the $\delta^{18} \mathrm{O}$ record, for example at 80 or 85 mbsf. Several candidate susceptibility peaks were examined, with the expectation that they might contain weak evidence of type- $\mathrm{B}$ or $\mathrm{C}$ behavior, possibly partly obscured by gradual diagenetic alteration. No such evidence was found.

The tight correlation between the "background" susceptibility variations and $\delta^{18} \mathrm{O}$ suggests that the susceptibility record may be helpful for interpreting the $\delta^{18} \mathrm{O}$ record. Peerdeman et al. (this volume) conclude that the $\delta^{18} \mathrm{O}$ peak at about $22 \mathrm{mbsf}$ represents oxygen isotope stage 4 . A susceptibility minimum exists at this depth, as expected for a negative correlation in Zone A. However, the larger susceptibility minimum at $18 \mathrm{mbsf}$ has no counterpart in the $\delta^{18} \mathrm{O}$ record. Were we to use the susceptibility record as a proxy $\delta^{18} \mathrm{O}$ record, then it would be logical to place stage 4 at about $18 \mathrm{mbsf}$, stage $5 \mathrm{~b}$ at about $22 \mathrm{mbsf}$, and stage $5 \mathrm{~d}$ at about $27 \mathrm{mbsf}$. This results in a satisfactory match with the reference isotope curves discussed by Peerdeman et al. Two different isotope-stage interpretations are presented by Peerdeman et al.: the first is based on a fairly uniform time scale, whereas the second has isotope stage 7 missing because of a hiatus at $\sim 40 \mathrm{mbsf}$ and a very long stage $8(\sim 40-71 \mathrm{mbsf})$. The latter
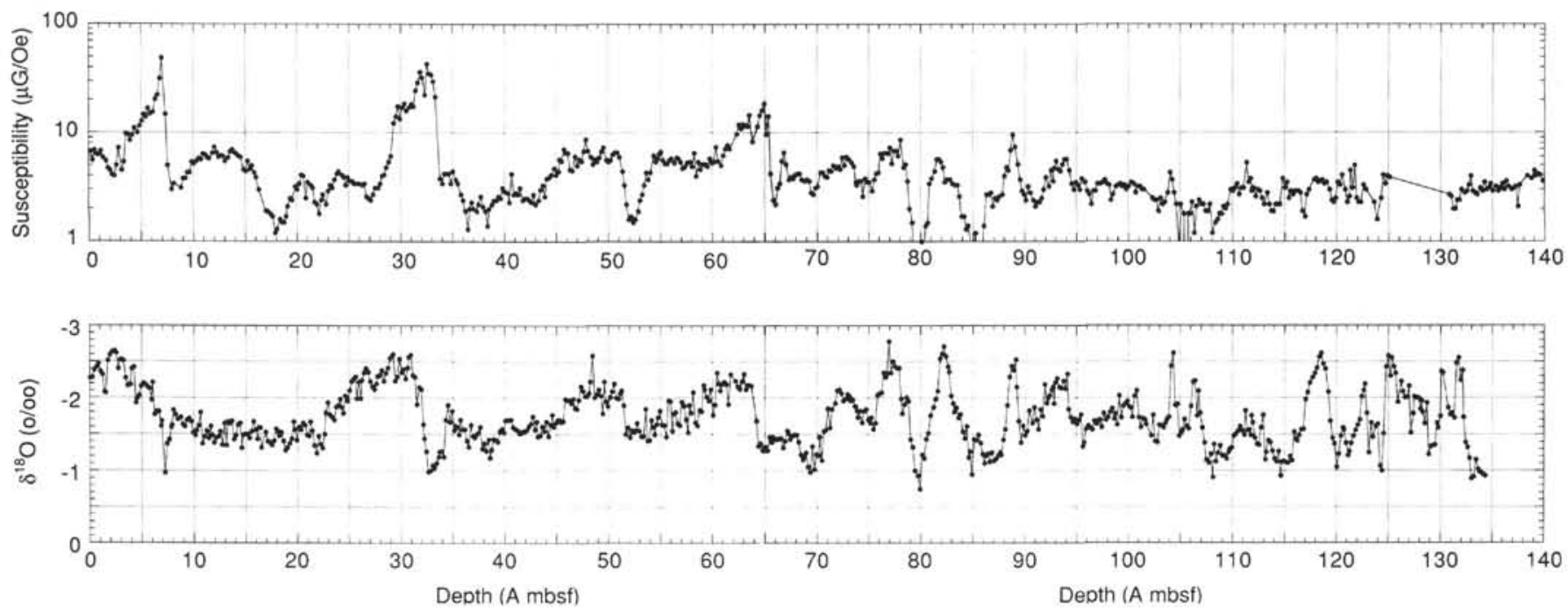

Figure 21. Comparison of the magnetic susceptibility log for Hole $820 \mathrm{~A}$ with the $\delta^{18} \mathrm{O}$ record of Peerdeman et al. (this volume). 
interpretation was proposed to be compatible with the biostratigraphic ages for the sequence. Based on the sort of susceptibility-proxy arguments used above, we found that the first interpretation is more consistent with the susceptibility data.

High values of $K_{f d}$ in the sharp susceptibility peaks (type-C behavior) suggest that an influx of ultrafine magnetic material occurred at a time of minimum sea level (glacial maximum) and early transgression. The conventional interpretation for this is that the ultra-fine material is wind-borne (Thompson and Oldfield, 1986). One might imagine that near the glacial maximum the quantity of wind-borne detritus from an arid continental Australia increased. However, studies of the fossil dune formations that cover $40 \%$ of Australia show that a counter-clockwise whorl-like wind system prevails under arid conditions (Wasson, 1986). These winds blow out to sea only from the southeast quadrant of the country and would be onshore in the northeast. An earlier study by Thiede (1979) of quartz (i.e., dust) contents in sediments off eastern Australia at the present time and during the last glacial maximum pointed to a similar conclusion. A wind-borne origin of the SP material in the susceptibility peaks therefore seems unlikely. An alternative scenario is that the SP grains were water-borne, and reflect a combination of changes in the sediment catchment regions at low sea levels, run-off conditions, and proximity of the shoreline. Another possibility is that the SP grains were produced in either the water or sediment column by chemical or biogenic processes. A bacterial origin cannot be ruled out, because dissolution of SD magnetite crystals may well have been capable of producing significant quantities of grains having sizes near those of the SP-SD threshold.

Despite the close inverse correlation with $\mathrm{CaCO}_{3}$ content (Fig. 9), we found that the observed susceptibility variations throughout the sequence cannot be fully accounted for by a simple carbonate dilution model. Possible reasons for this are (1) the dilution effect was underestimated by not considering other nonmagnetic components of the sediment, (2) there is a magnetic mineralogical dependence of susceptibility on the environmental conditions that control deposition (linked to oxygen isotope variations for example), or (3) the magnetic and carbonate accumulation rates are linked. In-situ production of biogenic magnetite (discussed below) might be a candidate for the latter, or possibly transport from nearshore regions of magnetically contaminated carbonate. We consider Reason 3 to be the most likely dominant factor.

The biomagnetic results are provocative, despite the fact that (1) only four samples were examined, (2) we do not know the absolute abundances, and (3) we do not know whether the biogenic magnetite was generated in-situ. If the magnetic content of the sediments (overall, or within certain characteristic zones) is predominantly of in-situ biogenic origin, then the hypothesis about the origin of the magnetic signals linked to the glacial and interglacial cycles and erosional dynamics must be completely revised. An explanation then has to be sought in terms of the paleoceanographic influence on temperature/nutritional/redox conditions conducive to the growth and extinction of populations of magnetic bacteria (proposed by Hesse, pers. comm., 1991).

\section{CONCLUSIONS}

The natural remanence of samples from Site 820 is dominated by a viscous remanent magnetization (VRM) acquired during the Brunhes Chron that obscures any primary reversal stratigraphy. AF cleaning is not effective in isolating a primary magnetization. The viscous remanence is attributed mainly to MD magnetite (using the name in a generic sense) with some contribution from SP grains.

Downcore variations in mineral magnetic properties are broadly characterized by (1) a surface zone ( $0-2 \mathrm{mbsf})$ of high, stable NRM with median destructive fields about 300 Oe and low susceptibility, attributed to a fine-grained, SD primary iron oxides; (2) three prominent high susceptibility peaks at 3.5 to $7.5 \mathrm{mbsf}$ (Peak 1), at 29.4 to
$33.5 \mathrm{mbsf}$ (Peak 2), and at 62.4 to $65.4 \mathrm{mbsf}$ (Peak 3) having similar morphologies; and (3) a relatively uniform, low-susceptibility background throughout the rest of the sequence. A close correlation exists between magnetic susceptibility and carbonate variations throughout the sequence, and also between susceptibility and $\delta^{18} \mathrm{O}$ in the upper 135 mbsf (isotope stages 1 through 20 ).

The magnetization in the surface zone (S) is thought to decay rapidly with depth as a result of sulfate reduction processes. The sharp susceptibility peaks coincide with low sea-level (glacial maximum) and early marine transgression conditions when an influx of ultra-fine (SP) material has been superimposed on a stable SD remanence (type-C magnetic properties). During subsequent late transgression condition, a stable SD remanence prevails, and the susceptibility gradually decreases to low values (type-B magnetic properties). During high sea levels and interglacial conditions, the stable SD remanence signal disappears, and the sediments give MD plus SP "background" magnetic properties (type-A).

Throughout most of the available record, a tight negative correlation exists between susceptibility and $\delta^{18} \mathrm{O}$. This switches to a positive correlation for the sharp susceptibility maxima (lowstands of sea level and early transgressions), with a gradual re-establishment of the negative correlation during the ensuing late transgressive phase. The overall strong negative correlation between carbonate contents and susceptibility also is modified at lowstands in sea level. The quality of the susceptibility $\delta^{18} \mathrm{O}$ correlation is such that the susceptibility record (which is simply and rapidly obtained) should be taken into account when interpreting the $\delta^{18} \mathrm{O}$ data. For example, the susceptibility record is more consistent with Peerdeman et al.'s first interpretation of oxygen isotope stage boundaries. The susceptibility record also suggests that isotope stages 4, 5b, and 5d (Shackleton, 1987, nomenclature) are poorly represented in the present $\delta^{18} \mathrm{O}$ record.

In the background zone, fluctuations in susceptibility and remanence were controlled predominantly, though not entirely, by variations in concentration, rather than by variations in magnetic composition. Carbonate dilution played an important role. Lower in the sequence, there is a cyclic occurrence of smaller amplitude, broad susceptibility peaks (e.g., at $193.5203,305$, and $338.5-358 \mathrm{mbsf}$ ), with magnetic properties that generally resemble the background zone, but contain large (by volume) high coercivity components. These coincide with the basal mud parts of repeated upward-coarsening cycles that occurred lower in the sequence and were related to variations in sea level. Conditions at these times must have been more oxic.

The depositional processes responsible for the rock magnetic properties of the sediments are a matter for speculation at this stage. Sulfate reduction processes were removing primary iron oxide particles from the upper part of the sequence and were probably contributing to a gradual MD shift in the grain-size spectrum in the background zone. The ultrafine component of the background zone could have arisen from the natural influx of finer material when the shoreline was more remote. A different sedimentary regime took over at low sea levels and during subsequent transgressions that produced sediments having a strong stable remanence. This must reflect a combination of changes in the sediment-catchment areas, near-shore sediment dynamics, runoff conditions, and greater proximity of the shoreline (consider the bathymetry in Fig. 1). The important observation that type-B and -C sediments were not produced during marine regressions prior to lowstands in sea level suggests that changing rainfall and run-off conditions were significant factors. This argument is strengthened by the low sedimentation rate that occurred leading up to the most recent glacial maximum (Peerdeman et al., this volume).

An arid continental wind-borne origin for the SP content of the sediments at low sea-level/early transgression conditions is discounted, but a convincing alternative explanation is difficult to find. If minimum sea-level conditions were established rapidly and lasted for only a short time (plausible), then the near-shore source regions for the water-borne terrigenous influx should be finer-grained and probably less well-consolidated. This, together with the effects of 
partial dissolution during sulfate reduction, might have led to an enhancement of SP grains.

Some preliminary evidence exists for the presence of biogenic magnetite, in relative abundances that match the overall magnetization of the sediments. If biogenic magnetite was a major component, then a completely different explanation for the magnetic properties of the sediments must be sought in terms of the factors that controlled productivity, preservation, and transport of the responsible organisms. The intriguing relationships among the various magnetic, geochemi$\mathrm{cal}$, and isotopic properties of the sediments at Site 820 clearly merit closer attention. In particular, some thorough rock magnetic work will be required to identify the magnetic minerals that are present (we adopted simplistic interpretations for the properties tested), and the importance of biogenic magnetite should be established. The phase relationships among susceptibility, $\delta^{18} \mathrm{O}$, and $\mathrm{CaCO}_{3}$ are highly significant and demonstrate the importance of high-resolution studies and dense sampling. We are fortunate that other sites $(821,819$, and 823 ) completed a transect outward across the continental slope. The key to understanding the results presented here will come, no doubt, from detailed comparisons among sites.

\section{ACKNOWLEDGMENTS}

We thank Steve Adamson for much assistance with laboratory work; also Peter Percival and David Edwards. Paul Hesse provided the biomagnetic results. Dave Clark and Michael Jackson made several valuable suggestions. This paper is published with the permission of the Director of the Australian Geological Survey Organisation.

\section{REFERENCES*}

Banerjee, S.K., King, J., and Marvin, J., 1981. A rapid method for magnetic granulometry with applications to environmental studies. Geophys. Res. Lett., 8:333-336.

Barton, C.E., and Bloemendal, J., 1986. Paleomagnetism of sediments collected during Leg 90, Southwest Pacific. In Kennett, J.P., von der Borch, C.C., et al., Init. Repts. DSDP, 90: Washington (U.S. Govt. Printing Office), 1273-1316.

Blakemore, R.P., and Frankel, R.B., 1981. Magnetic navigation in bacteria. Sci. Am., 245:58-65.

Davies, P.J., McKenzie, J.A., Palmer-Julson, A., et al., 1991. Proc. ODP, Init. Repts., 133: College Station, TX (Ocean Drilling Program).

Dekkers, M.J., 1988. Magnetic properties of natural pyrrhotite Part I: behavior of initial susceptibility and saturation magnetization-related rock-magnetic parameters in a grain-size dependent framework. Phys. Earth Planet. Int., 52:376-393.

Dunlop, D.J., 1973. Superparamagnetic and single-domain threshold sizes in magnetite. J. Geophys. Res., 78:1780-1793.
1983. Determination of domain structure in igneous rocks by alternating field and other methods. Earth. Planet. Sci. Lett., 63:353-367.

Hodych, J.P., 1991. Low-temperature demagnetization of saturation remanence in rocks bearing multidomain magnetite. Earth Planet. Sci. Lett., $66: 144-152$.

Karlin, R., and Levi, S., 1983. Diagenesis of magnetic minerals in recent hemipelagic sediments. Nature, 303:327-330.

King, J.W., Banerjee, S.K., Marvin, J., and özdemir, ö., 1982. A comparison of different magnetic methods for determining the relative grain size of magnetite in natural materials: some results from lake sediments. Earth Planet. Sci. Lett., 59:404-419.

Kneller, E.F., and Luborsky F.E., 1963. Particle size dependence of coercivity and remanence of single-domain particles. J. Appl. Phys., 134:656-658.

Kukla, G., Heller, F., Ming, L.X., Chun, X.T., Sheng, L.T., and Sheng, A.Z., 1988. Pleistocene climates in China dated by magnetic susceptibility. Geology, 16:811-814.

Lowrie, W., and Fuller, M., 1971. On the alternating field demagnetization characteristics of multidomain thermoremanent magnetization in magnetite. J. Geophys. Res., 76:6339-6349.

McElhinny, M.W., 1973. Palaeomagnetism and Plate Tectonics: Cambridge (Cambridge Univ. Press).

Potter D.K., and Stephenson, A., 1990. Field-impressed magnetic anisotropy in rocks. Geophys. Res. Lett., 17:2437-2440.

Shackleton, N.J., 1987. Oxygen isotopes, ice volume, and sea level. Quat. Sci. Rev., 6:183-190.

Shipboard Scientific Party, 1991. Site 820. In Davies, P.J., McKenzie, J.A., Palmer-Julson, A., et al., Proc. ODP, Init. Repts., 133 (Pt. 1): College Station, TX (Ocean Drilling Program), 509-568.

Thiede, J., 1979. Wind regimes over the late Quatenary southwest Pacific Ocean. Geology, 7:259-262.

Thompson, R., and Oldfield, F., 1986. Environmental Magnetism: London (Allen and Unwin).

Tivey M., and Johnson, P., 1984. The characterization of viscous remanent magnetization of pelagic clay. J. Geophys. Res., 95:4373-4382.

Wasson, R.J., 1986. Landforms. In Noble, J.C., and Bradstock, R.A. (Eds.), Mediterranean Landscapes in Australia: Mallee Ecosystems and Their Management. Aust., CSIRO, 13-34.

Yamazaki, T., Katsura, I., and Marumo, K., 1991. Origin of stable remanent magnetization of siliceous sediments in the central equatorial Pacific. Earth Planet. Sci. Lett., 105:8193. Abbreviations for names of organizations and publication titles in ODP reference lists
follow the style given in Chemical Abstracts Service Source Index (published by
American Chemical Society).

Date of initial receipt: 11 June 1992

Date of acceptance: 18 January 1993

Ms 133SR-261 